\title{
Hacia una edición crítica y estudio de los cuentos de Mauricio Magdaleno: El ardiente verano y otros cuentos
}

\section{Towards a Critical Edition and Study of Mauricio Magdaleno's Short Stories: El ardiente verano y otros cuentos}

\author{
Conrado J. Arranz Mínguez \\ Instituto Tecnológico Autónomo de México, México \\ conrado.arranz@itam.mx
}

RESUMEN

En la actualidad, una edición crítica completa no sólo debe ir acompañada de una crítica textual rigurosa, sino también de una genética que considere todos los testimonios. En este sentido, el presente trabajo analiza algunas de las problemáticas que se podrían producir si elaborásemos una edición crítica de todos los cuentos de Mauricio Magdaleno, dos de las más importantes serían las siguientes: primera, el hecho de que la mayor parte de los cuentos, tal y como los conocemos hoy, tuviera versiones previas publicadas en fuentes periódicas, lo cual nos obligaría a una investigación más exhaustiva y a una constitución del texto a partir de la colación de variantes de testimonios hemerográficos; segunda, la decisión de criterios que permitan superar la frontera genérica entre un relato costumbrista escrito a partir de una anécdota personal y un cuento susceptible de ser incluido en esta propuesta. Así, ambas problemáticas tienen como raíz común que la labor escritural más estable en la que se desempeñó Magdaleno fuera la periodística, ya que con ésta pudo compatibilizar otras actividades que, sobre todo, le servían para un propósito de sustento material. Una edición crítica de los cuentos de Mauricio Magdaleno otorgaría no sólo la seguridad de poder hacer una buena lectura del texto final, sino que también pondría de relieve el proceso creador del autor, lo cual ayudaría a superar la crítica anacrónica a la que se le ha sometido. Por último, y con base en el estado actual de la cuestión que se expone en este trabajo, se presenta una tabla con las versiones de los cuentos encontradas hasta ahora y otra con una propuesta sustentada de un posible índice de los cuentos que integrarían la edición crítica. 


\section{Palabras clave}

Crítica textual, crítica genética, edición crítica, Mauricio Magdaleno, cuento.

\section{AbSTRACT}

Currently, a complete critical edition must not only be accompanied by a rigorous textual criticism but also by a genetic edition that considers all the testimonies. In this sense, this work analyzes some of the problems that could occur if we publish a critical edition the entirety of Mauricio Magdaleno's short stories. There would be two important problems: first, the fact that most of the stories, as we know them today, had previous versions published in periodical sources, which would oblige us to make an exhaustive investigation and to gather and collate the texts from the varied hemerographic testimonies; second, the decision of any criterion that allows overcoming the generic border between a story written from a personal anecdote and a short story that can be included in our edition. Thus, both problems have as a common root: Magdaleno was a journalist and supplemented his journalistic career with other activities that served as material support. A critical edition of Mauricio Magdaleno's short stories would be a good reading of his work, and we could know about the author's creative process, which would help to overcome the anachronistic criticism that has been published on the topic. Finally, and based on the current status, we propose a table with the versions of the short stories found and another table with a proposal supported by a possible index of the short stories that would make up the critical edition.

\section{KEYWORDS}

Textual criticism, genetic criticism, critical edition, Mauricio Magdaleno, short story.

\section{RECEPCIÓN: 30/01/2021}

ACEPTACIÓN: 19/04/2021

\section{Introducción}

- 1 objetivo de este artículo es analizar la problemática en torno a la labor de SMauricio Magdaleno en la escritura de sus cuentos, presentar un estado de la cuestión actualizado y establecer las bases para una futura edición crítica de aquéllos. ${ }^{1}$

${ }^{1}$ Como no podía ser de otra forma, partimos de la investigación que provocó la escritura y sustentación de la tesis doctoral titulada "El universo literario de Mauricio Magdaleno (1906-1986)" (Arranz, 2014). Inevitablemente, el lector encontrará en este artículo algunas de 


\section{Hacia una edición crítica de los cuentos de Mauricio Magdaleno}

De forma tentativa, esta última tendría el título de El ardiente verano y otros cuentos para respetar así el nombre original que el autor dispuso en vida para su colección, e incorporar otros textos que, por diferentes razones, quedaron al margen de una edición libresca. Este trabajo, por un lado, describirá el desempeño de Mauricio Magdaleno en este subgénero narrativo a partir del sistema literario de la época para evitar ser objeto de una crítica anacrónica y, por otro, evidenciará el proceso creador del autor en estas narraciones, sustentado especialmente en una comunicación entre su trabajo periodístico y la composición final de la obra literaria, sin escapar a su propia biografia, que, como dice Alfonso Reyes en esa operación minuciosa de aproximación a la literacidad que es El deslinde, "entre las contadísimas existencias privadas que la biografía realmente recoge, ninguna, por oscura que sea, deja de dar luces respecto a una época, un país, una condición social, luces todas que van a iluminar la historia" (Reyes, 1963: 90). Por tanto, hacer una edición crítica de estos cuentos es también traslucir los procesos biográficos que inciden en la creación literaria, es decir, profundizar en el fuego de la historia, metáfora que empleó Pierre Nora para referirse a la memoria que recrea, a la necesidad de historia (Nora, 2008: 26).

El orden de este trabajo aspira a exponer de forma clara las problemáticas que enfrentaría un editor para fijar el corpus de la obra, las herramientas ecdóticas de las que dispondría y la contribución que supondría al conocimiento. En primer lugar, situamos la actividad cuentística de Mauricio Magdaleno en relación con su obra literaria y las particularidades principales que inciden en ella. En segundo lugar, establecemos el corpus de cuentos que escribió el autor, para lo cual analizamos algunas cuestiones que tienen que ver con la clasificación genérica. En tercer lugar, examina-

las premisas y razonamientos que se sostuvieron allí en relación con el subgénero narrativo del cuento en el escritor zacatecano, eso sí, dirigidas ahora al objetivo principal de proponer una edición crítica de todos ellos. No obstante lo anterior, la aparición de nuevo material de archivo, la detección de errores cometidos en aquella primera investigación, la publicación posterior de artículos que profundizaban en el análisis de algunos de los cuentos, nos permiten ahora actualizar el estado de la cuestión, desdecir o matizar algunas hipótesis sostenidas, aventurar otras de las cuales quizá nos retractaremos más tarde, merodear en definitiva — sin exactitud, pero con mayor profundidad - el ánimo literario de un autor que no nos fue contemporáneo, porque, como se ha manifestado en este espacio, "la investigación humanística se reconoce (debería reconocerse) inexacta. No digo: falsa; no digo: mendaz. Y su fruto, asimismo, espléndido. [...] su ratio es la tentativa, la aproximación" (Curiel, 2020: 32). Los trabajos que, desde aquella investigación, nos han permitido profundizar más en algunas - pocas - de estas narraciones son los siguientes: "Para permanecer en la frontera [estudio preliminar]" (Arranz, 2017a); "Variantes y variaciones en un cuento sobre la Revolución Mexicana: 'Teponaxtle', de Mauricio Magdaleno" (Arranz, 2017b), y "Mauricio Magdaleno y la memoria de Aguascalientes: entre la prensa periódica y la obra literaria", que se publicará este año bajo auspicio de la UNAM. 
mos de manera pormenorizada la única publicación de sus cuentos en forma libresca y el hecho de que ésta se produjera en 1954. En cuarto y último lugar, comentamos la metodología y criterios que seguiríamos ante una eventual edición crítica, y proponemos un índice tentativo de ésta.

\section{Un autor en los márgenes de la creación literaria, la prensa y la política}

Es notoria la ausencia de estudios especializados en relación con la vasta obra del escritor Mauricio Magdaleno (1906-1986), una producción heterogénea compuesta por siete novelas, un volumen de cuentos, uno de teatro y varias obras de revista, hasta trece libros de carácter ensayístico, numerosos prólogos e introducciones, al menos sesenta participaciones en guiones de cine y, sobre todo, más de mil quinientos artículos o columnas periodísticas en publicaciones periódicas, tales como El Demócrata, El Nacional, El Universal, Todo, El Libro y el Pueblo, América, Excélsior, Novedades, La Prensa y El Día, entre otras. De hecho, la actividad periodística fue la que con más regularidad cultivó a lo largo de su trayectoria profesional, entre 1933 y $1985 .{ }^{2}$ Esta característica es tan relevante que muchos de sus libros de ensayos, como Ritual del año (1955), La voz y el eco (1964) y Agua bajo el puente (1968), por citar algunos ejemplos, e incluso de crónicas, como Las palabras perdidas (1956), están formados a partir de variantes o desarrollos de los textos publicados originalmente en periódicos o revistas. A su vez, la mayor parte de los cuentos fueron dados a conocer en estos medios y, como ya hemos podido comprobar, ${ }^{3}$ algunos de ellos también dialogaron o se materializaron a partir de otros artículos periodísticos de índole ya sea biográfica o ya costumbrista.

Estos textos de carácter periódico que Magdaleno difundía en la prensa seguían diferentes temas y objetivos. A grandes rasgos, y sin contar las publicaciones de cuentos o incluso de fragmentos de novelas, se podrían clasificar en cuatro tipos: los de apreciación estética o de crítica artística, en cuanto que valoraba la labor creativa de otros (pintores, escritores, músicos); los cronísticos, de tipo provinciano o urbano, en los que recurría a la descripción de aspectos cotidianos que observaba, muchas veces a partir de viajes; los de carácter histórico, especialmente en referencia al pasado nacional; y los

\footnotetext{
${ }^{2}$ Registramos el periodo de tiempo en el que Magdaleno comenzó a escribir y a publicar asiduamente en la prensa, si bien ya desde 1927 él mismo declaraba ser "periodista" en algunos documentos privados custodiados en su archivo familiar. Incluso, la investigadora Virginia Medina Ávila afirma que el escritor trabajó como editorialista de abril a mayo de 1923 y como redactor y compilador de febrero a octubre de ese mismo año (Medina, 1998: 19).

${ }^{3}$ Nos referimos al artículo que se publicará este año, mencionado en la nota 1 del presente trabajo: "Mauricio Magdaleno y la memoria de Aguascalientes: entre la prensa periódica y la obra literaria".
} 


\section{Hacia una edición crítica de los cuentos de Mauricio Magdaleno}

de opinión política, sin duda los menos valiosos, por cuanto una gran parte de ellos respondían al compromiso institucional que Magdaleno sentía al ostentar cargos públicos.

La carrera literaria de Mauricio Magdaleno estuvo marcada por la búsqueda del género que le sirviera como cauce de expresión de los problemas existenciales del ser humano y la necesidad de poner éstos en relación con el contexto histórico de México. De hecho, en sus primeros años de carrera, el escritor zacatecano transitó por prácticamente todos los géneros literarios, a excepción de la poesía. Como él mismo siempre lo reconoció, las dificultades económicas truncaron su proyección literaria y lo arrinconaron, por un lado, a la asunción de funciones de responsabilidad pública cada vez más elevadas y, por otro, a la participación en la industria cinematográfica. ${ }^{4}$ En esta última pudo dar cauce a su talento creativo, pero no sin afrontar las imposiciones de carácter mercantil. De cualquier modo, Mauricio Magdaleno nunca abandonó su trabajo como escritor en medios periodísticos, y ésta fue la forma de no perder el pulso de la labor intelectual y cultural, de la que ya había sido relegado por su escasa actividad estrictamente literaria, mucho más desde los años cincuenta. Por supuesto, entendemos que esa relegación se produjo a partir de los juicios de valor de una ideología social dominante en la crítica literaria del momento, ${ }^{5}$ circunstancia que, de manera atinada, observó Eagleton al preguntarse qué era la literatura (Eagleton, 2014: 28); sin embargo, el propio teórico inglés entendió el fenómeno literario, de un modo más amplio, "como las diferentes formas en que la gente se relaciona con lo escrito" (Eagleton, 2014: 20). Y Mauricio Magdaleno jamás dejó de relacionarse con su propia escritura, jamás perdió el pulso en ese sentido.

Los cuentos, subgénero narrativo capaz de condensar en espacio y tiempo la labor creativa, fueron un alegato de luz ficcional en su producción literaria. Algunas de las características que podrían definir el estilo de Mauricio Magdaleno (el uso de recursos metafóricos y de una adjetivación prolífica, el respeto a la tradición literaria mexicana y su diálogo con ella, la lectura de la realidad cotidiana con una melancolía hacia el pasado y cierta implicación política, entre otras) lo convierten en un autor representa-

${ }^{4}$ En este sentido, y tan sólo por poner un ejemplo, en una entrevista con Silvia Molina, Magdaleno afirmaría: "No [entré al cine] porque me gustara. Entré por necesidades económicas, estaba en tratos con Agustín Fink cuando me llegó una carta que firmaba Alejandro Gómez Arias diciendo que el ministro de Educación me agradecía muy de veras los eficientes servicios que había prestado en el Departamento de Bibliotecas. Era un cese... pero mira, al jefe de ese departamento le pagaban 700 pesos y acá, por aprender, me daban cinco mil. Pues aquí me quedé" (Molina, 1981: 3).

${ }^{5}$ La posición de Magdaleno era ambivalente. Por un lado, era la de un escritor que formaba parte del establecimiento político, quizá desencantado, pero, al fin y al cabo, sobreviviente gracias al mismo. Por otro lado, representaba a una generación que por aquellos años parecía ya superada: la del realismo social regionalista, vinculada con los resultados de la Revolución. 
tivo del siglo xx mexicano, especialmente en cuanto al análisis de dos circunstancias interrelacionadas que incidían en el proceso creativo de la mayor parte de los escritores: cierto control político de un Estado en construcción y la imposibilidad de gozar de una autonomía material como creador. Sin duda, sus cuentos se constituyeron a partir del entramado de todas estas tensiones o circunstancias y, como dijimos antes, el análisis de sus variantes supone una perspectiva privilegiada para desentrañarlas.

\section{2. ¿Cuáles son los cuentos de Mauricio Magdaleno? Problemáticas y retos}

Mauricio Magdaleno esperó mucho tiempo hasta ver la publicación de una colección de sus cuentos, en concreto hasta $\mathrm{El}$ ardiente verano (Fondo de Cultura Económica, 1954). De manera póstuma, también hubo un intento loable por rescatar del olvido dichas narraciones, en concreto el de Cuentos completos (Lectorum, 2003). Aunque más adelante trataremos el contenido de dichas ediciones - especialmente de la primera, por ser la única en vida del autor-, es necesario destacar que ninguna incluye un estudio preliminar o un anexo documental que explique la génesis de los cuentos coleccionados, a pesar de que, hasta el momento, nuestras investigaciones demuestran que sólo tres de los trece cuentos recogidos en la edición del Fondo de Cultura Económica supusieron estrictamente una novedad editorial, ${ }^{6}$ como podemos observar en la Tabla 1. Esta ausencia de investigación provoca desajustes más graves en el caso de los Cuentos completos, los cuales enumeramos aquí: colecciona los cuentos sin respetar el orden de El ardiente verano - ni explicar con base en qué criterios lo altera-; anuncia un cuento inédito que no era tali, deja sin recopilar otros posteriores a El ardiente verano que habían sido publicados en vida del autor; ${ }^{8}$ recoge dos que Mauricio Magdaleno

\footnotetext{
${ }^{6}$ Eso sí, también es cierto que dos cuentos, "El caimán” y "Viernes Santo en Ixtapalapa", se publicaron tan sólo ocho meses antes que la edición de El ardiente verano, si atendemos a la fecha del 20 de noviembre que aparece en el colofón de la primera edición. En ese caso, podríamos considerarlos como un adelanto editorial, incluso con un objetivo comercial; sin embargo, en el caso de "El caimán" hay variables notorias que tienen que ver con el proceso editorial que llevaron a cabo los editores del Fondo de Cultura, especialmente con estos cuentos que formaron el ciclo que denominamos de Aguascalientes. A diferencia de "El caimán", y sin hacer una colación exhaustiva, las dos versiones de "Viernes Santo en Ixtapalapa" prácticamente son idénticas, más allá de la corrección de algunos signos de puntuación y de algunas modificaciones de carácter tipográfico, como, por ejemplo, poner el nombre de las tiendas en cursiva en lugar de entrecomillado.

${ }^{7}$ Nos referimos a "Las campanas de San Felipe", que ya se había publicado hasta en dos ocasiones, en 1981 y 1994, como podemos observar en la Tabla 1.

${ }^{8}$ Nos referimos en concreto a tres cuentos: "Lunario de la calle del Ahorcado", publicado por primera y única vez en 1975; "Un vecino de Jerez", publicado en vida del autor hasta
} 


\section{Hacia una edición crítica de los cuentos de Mauricio Magdaleno}

- o sus editores - dejó deliberadamente fuera de El ardiente verano; ${ }^{9}$ no contempla otros dos cuentos, "LLas mañanas de Schaharazada]" y "El poder secreto". ${ }^{10}$ Como se puede advertir, son muchas las incógnitas que se abren alrededor de esta edición que aspira a coleccionar los cuentos completos; pero también se abren algunas otras que implican al propio Magdaleno en relación con El ardiente verano: ¿por qué dejó fuera "El compadre Mendoza" y "El baile de los pintos"?, o ¿por qué no incluyó "El poder secreto" si fue el primero de los cuentos que publicó consecutivamente en la revista Hoy entre 1941 y 1942? ${ }^{11}$ Sobre la primera pregunta, quizá podríamos pensar que el autor entendió que ya habían sido compilados dentro de un libro (Concha Bretón, Botas, 1936) o que los consideró más extensos que el resto, lo cual los aproximaba al subgénero de novela corta. A la segunda pregunta dedicaremos una reflexión más adelante.

Entendemos que las anteriores circunstancias, sin atender aún al resultado del cotejo de variantes entre las diferentes versiones, ya representan por sí mismas un llamado vigoroso a ordenar la génesis y la recepción crítica de la narrativa corta de Magdaleno, y también a aprovechar dichos trabajos filológicos para reflexionar sobre el contenido de ésta y su inclusión en el sistema literario de la época. Esto, sin duda, ayudaría a valorar, de forma más justa al menos, la obra del escritor y su proceso creativo, siempre en diálogo con la historia nacional y la actualidad, como él mismo constató en El compromiso de las letras, ${ }^{12}$ al preguntarse si no le concernían a la literatura "las más informes distorsiones y los gritos del deliquio en que se expresa una porción del destino del hombre moderno" (Magdaleno, 1958: 20).

en tres ocasiones (1979, 1981 y 1985); y "La bata", último cuento del escritor, publicado en 1985, meses antes de su fallecimiento. La ausencia de estudios sobre la génesis de los relatos provoca también algunos comentarios anacrónicos de Eduardo Antonio Parra en el prólogo, y demerita un texto que, en realidad, analiza con éxito y elocuencia el contenido de los relatos y sintetiza de forma magistral la relevancia de Mauricio Magdaleno para la literatura mexicana del siglo xx, a pesar de cometer al final el error de la atribución del guion de La perla a Magdaleno (Parra, 2003: 17).

${ }^{9}$ Nos referimos a "El compadre Mendoza" y "El baile de los Pintos", ambos publicados por primera vez en El Nacional en 1934.

${ }^{10}$ Aunque en estos casos entendemos que los editores pudieron desconocer la existencia de ambos.

${ }^{11}$ Eso sí, podríamos entender que no incluyera "[Las mañanas de Schaharazada]" al tratarse de un cuento que se publicó cuando él era demasiado joven — apenas 21 años - e intentaba hacerse de un nombre literario por medio de los concursos periodísticos.

${ }^{12}$ Corresponde al discurso de recepción como individuo de número de la Academia Mexicana de la Lengua, que fue leído el 14 de junio de 1957 y contestado por Antonio Castro Leal. 
Tabla 1. Versiones de los cuentos de Mauricio Magdaleno

(Orden cronológico de publicación)

\begin{tabular}{|c|c|c|}
\hline Nombre del cuento* & $\begin{array}{l}\text { Año } \\
1^{\mathrm{a}} \mathrm{v} .\end{array}$ & Lugar de publicación ${ }^{* *}$ \\
\hline $\begin{array}{l}\text { [Las mañanas } \\
\text { de Schaharazada] }\end{array}$ & 1927 & El Demócrata, 3 de septiembre de 1925, pp. 3 y 4. \\
\hline $\begin{array}{l}\text { Teponaxtle } \\
\text { [Aquella noche }] \\
{[\text { Una noche prodigiosa }]^{* * *}}\end{array}$ & 1933 & $\begin{array}{l}\text { "Aquella noche", Estampa, año 6, núm. 264, Madrid, } 28 \\
\text { de enero de 1933, pp. 37-38. } \\
\text { "Una noche prodigiosa", Hoy, No. 279, } 27 \text { de junio de } \\
\text { 1942, pp. 48-49. // "Teponaxtle" en El ardiente verano, Mé- } \\
\text { xico, Fondo de Cultura Económica (Letras Mexicanas, } \\
\text { 17), 1954, pp. 174-187. // "Teponaxtle" en María Elvira } \\
\text { Bermúdez (introducción, selección y notas), Narrativa mexi- } \\
\text { cana revolucionaria, Lima, Editorial Ecoma, 1974, pp. 225-233. } \\
\text { // "Teponaxtle" en Cuentos completos (pról. Eduardo Antonio } \\
\text { Parra), México, Lectorum, 2003, pp. 151-160. // "Tepo- } \\
\text { naxtle" en Conrado J. Arranz (selección y estudio prelimi- } \\
\text { nar), Cuentos de la Revolución Mexicana, Querétaro, UAQ, 2017, } \\
\text { pp. 37-52. }\end{array}$ \\
\hline El compadre Mendoza & 1934 & $\begin{array}{l}\text { El Nacional (Suplemento dominical), N }{ }^{\circ} \text {. 153, } 25 \text { de } \\
\text { marzo de 1934, pp.1 y 5; El Nacional (Supl. dom.), No.154, } \\
1^{\circ} \text { de abril de 1934, p. 1. } \\
\text { El compadre Mendoza, México, s/e, 1934. // en Concha Bre- } \\
\text { tón, México, Botas, 1936, pp. 145-182. // en El resplandor y } \\
\text { El compadre Mendoza, México, Promexa, } 1979 \text { (Clásicos de } \\
\text { la Literatura Mexicana; prólogo de Raúl Cardiel Reyes), } \\
\text { pp. 269-286. // en La novela de la Revolución (presentación de } \\
\text { Roberto Suárez), México, Promexa, 1985, pp. 781-800. // } \\
\text { en Xorge Del Campo (ed. y pról.), Cuentistas de la Revolución } \\
\text { Mexicana, T. IV, México, Comisión Nacional para las Cele- } \\
\text { braciones del 175 Aniversario de la Independencia Nacional } \\
\text { y } 75 \text { Aniversario de la Revolución Mexicana (Secretaría de } \\
\text { Gobernación), 1985, pp. 55-75. // en La novela de la Revolución } \\
\text { [presentación de Roberto Suárez], México, Promexa, 1985, } \\
\text { pp. 781-800. // en Cuentos completos (pról. Eduardo Antonio } \\
\text { Parra), México, Lectorum, 2003, pp. 109-128. // en Con- } \\
\text { rado J. Arranz (selección y estudio preliminar), Cuentos de la } \\
\text { Revolución Mexicana, Querétaro, UaQ, 2017, pp. 53-81. }\end{array}$ \\
\hline
\end{tabular}

* Mantenemos, en negrita, el nombre de la versión definitiva del cuento y, en su caso, recuperamos entre corchetes y con una letra de tamaño menor los de versiones anteriores.

** Destacamos las primeras versiones de los cuentos, mientras que con un tamaño de letra menor y de forma consecutiva registramos las versiones posteriores. En caso de que el cuento haya tenido varios títulos, recuperamos el nombre entre comillas, en el caso contrario, lo eludimos.

*** Aquí el nombre está entre corchetes porque el autor no se lo puso, de modo que éste corresponde al título de la columna de El Demócrata en la que fue publicado. 


\begin{tabular}{|c|c|c|}
\hline El baile de los Pintos & 1934 & $\begin{array}{l}\text { El Nacional (Suplemento dominical), No. 162, } 27 \text { de } \\
\text { mayo de 1934, p. 1; El Nacional (Supl. dom.), N. } 163,3 \\
\text { de junio de 1934, p. } 1 . \\
\text { en Concha Bretón, México, Botas, 1936, pp. 183-210. // en } \\
\text { Cuentos completos (pról. Eduardo Antonio Parra), México, Lec- } \\
\text { torum, 2003, pp. 129-142. // en Conrado J. Arranz (selec- } \\
\text { ción y estudio preliminar), Cuentos de la Revolución Mexicana, } \\
\text { Querétaro, UaQ, 2017, pp. 53-81. }\end{array}$ \\
\hline $\begin{array}{l}\text { Pasos a mi espalda } \\
{[\text { Pasos }]}\end{array}$ & 1934 & $\begin{array}{l}\text { "Pasos", El Nacional (Suplemento dominical), } 12 \text { de } \\
\text { agosto de 1934, p. } 1 . \\
\text { "Pasos a mi espalda", Novedades. México en la Cultura, no. 135, } \\
2 \text { de septiembre de } 1951 \text {, pp. } 3 \text { y 8. // "Pasos a mi espalda" } \\
\text { en El ardiente verano, México, Fondo de Cultura Económica } \\
\text { (Letras Mexicanas, 17), 1954, pp. 202-216. // "Pasos a mi } \\
\text { espalda" en María del Carmen Millán (selecc. y presenta- } \\
\text { ción), Antología de cuentos mexicanos, T. I, México, Secretaría } \\
\text { de Educación Pública (SepSetentas Vols. 292-294), 1976, } \\
\text { pp. 117-129 [2 edición: México, Editorial Nueva Imagen, } \\
\text { 1977, T. I, pp. 89-97; 3" edición: México, Editorial Nueva } \\
\text { Imagen, 2006, T. I, pp. 121-148]. // "Pasos a mi espalda" } \\
\text { en Cuentos completos (pról. Eduardo Antonio Parra), México, } \\
\text { Lectorum, 2003, pp. 39-49. }\end{array}$ \\
\hline $\begin{array}{l}\text { El ardiente verano } \\
\text { [Segundo turno] } \\
{[\text { Mexicanos en Texas }]}\end{array}$ & 1941 & $\begin{array}{l}\text { "Segundo turno", Hoy, No. 220, } 10 \text { de mayo de 1941, } \\
\text { pp. 48-49 y } 82 . \\
\text { "Mexicanos en Texas", Cuadernos Americanos, Vol. VI, no. 1, } \\
\text { enero-febrero de 1943, México D. F., pp. 229-240. // "El ar- } \\
\text { diente verano" en El ardiente verano, México, Fondo de Cultura } \\
\text { Económica (Letras Mexicanas, 17), 1954, pp. 7-39. // "El } \\
\text { ardiente verano" en Cuentos completos (pról. Eduardo Antonio } \\
\text { Parra), México, Lectorum, 2003, pp. 217-239. }\end{array}$ \\
\hline El poder secreto & 1941 & Hoy, $\mathrm{N}^{\circ} .229,21$ de junio de 1941, pp. 42 y 74. \\
\hline Leña verde & 1941 & $\begin{array}{l}\text { Hoy, No. 244, } 25 \text { de octubre de 1941, pp. 60-61. } \\
\text { Mundo. Una revista para todo el mundo, Vol. I, no. 1, México D. F., } \\
\text { abril de 1945, pp. 8-14. // en José Mancisidor (ed. y pról.), } \\
\text { Cuentos mexicanos de autores contemporáneos, México, Nueva España } \\
\text { (Colección Atenea), s/f [1945?], pp. 491-500. // en El ardiente } \\
\text { verano, México, Fondo de Cultura Económica (Letras Mexica- } \\
\text { nas, 17), 1954, pp. 188-201. // "Bois Vert", Europe, 37 année, } \\
\mathrm{n}^{\circ} \text {. 367-368, littérature mexicaine, noviembre-diciembre de } \\
\text { 1959, pp. 41-49. // en María Elvira Bermúdez (introducción, } \\
\text { selección y notas), Narrativa mexicana revolucionaria, Lima, Edito- } \\
\text { rial Ecoma, 1974, pp. 234-241. // en Doce escritores y un tema, la } \\
\text { Revolución mexicana, México, Editorial Popular de los Trabajado- } \\
\text { res, 1978, pp. 233-247. // [fragmentos] en Severo Mirón (ed.), } \\
\text { Platícame un libro, No. 69, México, Editorial Limusa (Noriega } \\
\text { editores), 1990, pp. 29-32. // en Cuentos completos (pról. Eduar- } \\
\text { do Antonio Parra), México, Lectorum, 2003, pp. 161-170. } \\
\text { // en Leña verde, México, Universidad Nacional Autónoma } \\
\text { de México (Material de Lectura - Serie Cuento Contem- } \\
\text { poráneo), 2010. // en Conrado J. Arranz (selección y estu- } \\
\text { dio preliminar), Cuentos de la Revolución Mexicana, Querétaro, } \\
\text { usQ, 2017, pp. 105-120. }\end{array}$ \\
\hline
\end{tabular}




\begin{tabular}{|c|c|c|}
\hline $\begin{array}{l}\text { Estrellas de noviembre } \\
\text { [Fruta del tiempo] }\end{array}$ & 1942 & $\begin{array}{l}\text { "Fruta del tiempo", Hoy, No. 270, } 25 \text { de abril de 1942, } \\
\text { pp. 48-49. } \\
\text { "Estrellas de noviembre" en El ardiente verano, México, Fondo de } \\
\text { Cultura Económica (Letras Mexicanas, 17), 1954, pp. 148-163. } \\
\text { // "Estrellas de noviembre" en Cuentos completos (pról. Eduardo } \\
\text { Antonio Parra), México, Lectorum, 2003, pp. 183-193. }\end{array}$ \\
\hline $\begin{array}{l}\text { Llamarada } \\
\text { [Polvo del arrabal] } \\
{[\text { El rey del fuego }]}\end{array}$ & 1942 & $\begin{array}{l}\text { "Polvo del arrabal", Hoy, No. 293, } 3 \text { de octubre de } \\
\text { 1942, pp. 48-49 y 82. } \\
\text { "El rey del fuego" en José Mancisidor (ed. y pról.), Cuentos } \\
\text { mexicanos de autores contemporáneos, México, Nueva España (Co- } \\
\text { lección Atenea), s/f [1945?], pp. 480-490. // "Llamarada" } \\
\text { en El ardiente verano, México, Fondo de Cultura Económica } \\
\text { (Letras Mexicanas, 17), 1954, pp. 135-147. // "Il Re del } \\
\text { Fuoco" ["El rey del fuego"] en Antonio García Andreu (ant.), } \\
\text { Carosello di narratori ispano americani, Milán, Aldo Martello edi- } \\
\text { tore milano, 1959, pp. 235-245. // "Llamarada" en Cuentos } \\
\text { completos (pról. Eduardo Antonio Parra), México, Lectorum, } \\
\text { 2003, pp. 195-203. }\end{array}$ \\
\hline $\begin{array}{l}\text { Palo ensebado**** } \\
\text { [El palo ensebado] }\end{array}$ & 1945 & $\begin{array}{l}\text { "El palo ensebado", Mundo. Una revista para todo el mundo, } \\
\text { Vol. II, No. 9, México D.F., diciembre de 1945, pp. 14-18. } \\
\text { "Palo ensebado" en El ardiente verano, México, Fondo de Cul- } \\
\text { tura Económica (Letras Mexicanas, 17), 1954, pp. 164-173. } \\
\text { // "Palo ensebado" en Fernando Curiel, Francisco Guzmán } \\
\text { y Margo Glantz, Los hïjos de la Revolución. Cada veinte años. Cuen- } \\
\text { tistas mexicanos del siglo XX, México, Delegación Venustiano Ca- } \\
\text { rranza (Colección "Práctica de Vuelo"), 1984, pp. 77-83. // } \\
\text { "Palo ensebado" en Cuentos completos (pról. Eduardo Antonio } \\
\text { Parra), México, Lectorum, 2003, pp. 143-150. // en Con- } \\
\text { rado J. Arranz (selección y estudio preliminar), Cuentos de la } \\
\text { Revolución Mexicana, Querétaro, UAQ, 2017, pp. 121-132. }\end{array}$ \\
\hline El héroe de Peñuelas & 1948 & $\begin{array}{l}\text { México en el Arte, No. 1, julio de 1948, pp. 13-16. } \\
\text { en El ardiente verano, México, Fondo de Cultura Económica (Le- } \\
\text { tras Mexicanas, 17), 1954, pp. 120-134. // en María del Car- } \\
\text { men Millán (selecc. y presentación), Antología de cuentos mexicanos, } \\
\text { T. I, México, Secretaría de Educación Pública (SepSetentas } \\
\text { Vols. 292-294), 1976, pp. 130-143 [2ª edición: México, Edito- } \\
\text { rial Nueva Imagen, 1977, T. I, pp. 98-107; 3a edición: México, } \\
\text { Editorial Nueva Imagen, 2006, T. I, pp. 121-148]. // en Cuentos } \\
\text { de la provincia, México, SEP/Conasupo (Cuadernos Mexicanos, } \\
\text { 84, Año II), s/a, pp. 3-17. // en Miguel Ángel Leal Menchaca } \\
\text { (ant.), La rasgadura del velo: narradores latinoamericanos del siglo XX, } \\
\text { Chapingo (México), Universidad Autónoma Chapingo-Edi- } \\
\text { ciones Molino de Letras (Serie Malitzin), 2003, pp. 45-57. // } \\
\text { en Cuentos completos (pról. Eduardo Antonio Parra), México, } \\
\text { Lectorum, 2003, pp. 171-181. }\end{array}$ \\
\hline
\end{tabular}

**** En el archivo encontramos una referencia que indica que este cuento fue publicado en el diario argentino La Nación; sin embargo, no lo hemos localizado (Tiempo, 1939). 


\begin{tabular}{|c|c|c|}
\hline El caimán & 1954 & $\begin{array}{l}\text { Universidad de México, Vol. VIII, número 7, marzo de } \\
\text { 1954, pp. 8-10. } \\
\text { en El ardiente verano, México, Fondo de Cultura Económica } \\
\text { (Letras Mexicanas, 17), 1954, pp. 85-99. // en Anuario del } \\
\text { cuento mexicano (1954), México D. F., Instituto Nacional de } \\
\text { Bellas Artes, 1955, pp. 345-358. // en Mariano Baquero Go- } \\
\text { yanes (ed.), Antología de cuentos contemporáneos, Barcelona - Ma- } \\
\text { drid - Buenos Aires - Río de Janeiro - México - Monterrey, } \\
\text { Editorial Labor, 1964, pp. 390-395. // en Cuentos completos } \\
\text { (pról. Eduardo Antonio Parra), México, Lectorum, 2003, } \\
\text { pp. 97-107. }\end{array}$ \\
\hline $\begin{array}{l}\text { Viernes Santo } \\
\text { en Ixtapalapa }\end{array}$ & 1954 & $\begin{array}{l}\text { América: revista antológica, Núm. 69, marzo de 1954, Mé- } \\
\text { xico D.F., pp. 54-64. } \\
\text { en El ardiente verano, México, Fondo de Cultura Económica } \\
\text { (Letras Mexicanas, 17), 1954, pp. 217-233. // en Cuentos } \\
\text { completos (pról. Eduardo Antonio Parra), México, Lectorum, } \\
\text { 2003, pp. 205-216. }\end{array}$ \\
\hline Cuarto año & 1954 & $\begin{array}{l}\text { El ardiente verano, Fondo de Cultura Económica (Letras } \\
\text { Mexicanas, 17), 1954, pp. 40-59. } \\
\text { en Antonio Acevedo Escobedo (sel. y pról.), Letras sobre Aguas- } \\
\text { calientes, México, Editorial Stylo, 1963, pp. 297-321. // en } \\
\text { Emmanuel Carballo (ed.), El cuento mexicano del siglo XX, Mé- } \\
\text { xico, Empresas Editoriales, 1964, pp. 253-266. // en Cuentos } \\
\text { de la provincia, México, sEP/Conasupo (Cuadernos Mexicanos, } \\
\text { 84, Año II), s/a, pp. 18-32. // en Alicia Molina, Del aula y sus } \\
\text { muros. Cuentos, México D. F., sEP - Ediciones El Caballito - } \\
\text { Dirección General de Publicaciones (Biblioteca Pedagógica), } \\
\text { 1985, pp. 141-158. // en Cuentos completos (pról. Eduardo An- } \\
\text { tonio Parra), México, Lectorum, 2003, pp. 65-78. }\end{array}$ \\
\hline Las carretelas & 1954 & $\begin{array}{l}\text { El ardiente verano, Fondo de Cultura Económica (Letras } \\
\text { Mexicanas, 17), 1954, pp. 60-84. } \\
\text { en Antonio Acevedo Escobedo (sel. y pról.), Letras sobre Aguas- } \\
\text { calientes, México, Editorial Stylo, 1963, pp. 297-321. // en } \\
\text { Cuentos completos (pról. Eduardo Antonio Parra), México, Lec- } \\
\text { torum, 2003, pp. 79-96. }\end{array}$ \\
\hline Las Víboras & 1954 & $\begin{array}{l}\text { El ardiente verano, Fondo de Cultura Económica (Letras } \\
\text { Mexicanas, 17), 1954, pp. 100-119. } \\
\text { en Cuentos completos (pról. Eduardo Antonio Parra), México, } \\
\text { Lectorum, 2003, pp. 51-64. }\end{array}$ \\
\hline
\end{tabular}




\begin{tabular}{|l|l|l|}
\hline $\begin{array}{l}\text { Lunario de la calle } \\
\text { del Ahorcado }\end{array}$ & $1975 \begin{array}{l}\text { Anuario } 1975 \text { del Seminario de Cultura Mexicana, México, } \\
\text { Ediciones del Seminario de Cultura Mexicana, 1975, } \\
\text { pp. 99-109. }\end{array}$ \\
\hline Un vecino de Jerez & 1979 & $\begin{array}{l}\text { Anuario } 1979 \text { del Seminario de Cultura Mexicana, México, } \\
\text { Ediciones del Seminario de Cultura Mexicana, 1979, } \\
\text { pp. 93-103. } \\
\text { Proceso, no. 266, 7 de diciembre de 1981, pp. 44-46. // Excélsior. } \\
\text { La Cultura al Día, 29 de noviembre de 1985, pp. 1 y 4; y Excél- } \\
\text { sior. La Cultura al Día, 4 de diciembre de 1985, pp. 1 y 4. }\end{array}$ \\
\hline $\begin{array}{l}\text { Las campanas } \\
\text { de San Felipe }\end{array}$ & 1981 & $\begin{array}{l}\text { Sábado [suplemento de Unomásuno], n'. 214, 12 de di- } \\
\text { ciembre de 1981, pp. 4-6. } \\
\text { en Memorias de la Academia Mexicana Correspondiente a la Española, } \\
\text { Tomo XXV (1981-1987), México, Academia Mexicana, 1994, } \\
\text { pp. 345-358. // en Cuentos completos (pról. Eduardo Antonio } \\
\text { Parra), México, Lectorum, 2003, pp. 19-37. }\end{array}$ \\
\hline La bata & 1985 & \begin{tabular}{l} 
Punto, no ${ }^{\circ}$. 144, 5-11 de agosto de 1985, pp. 17-18. \\
\hline
\end{tabular} \\
\hline
\end{tabular}

Fuente: Elaboración propia.

A pesar de haber realizado una búsqueda lo más exhaustiva posible en la biblioteca y en el archivo del escritor, así como en diferentes hemerotecas, cabe la posibilidad de que existan más contribuciones del autor en este subgénero narrativo, motivo por el cual es necesario, en primer lugar, ampliar la búsqueda a nuevos suplementos culturales o revistas especializadas. De hecho, poseemos testimonios indirectos que evidencian la existencia de nuevos relatos o, al menos, otras versiones. Por ejemplo, entre 1936 y 1945, Mauricio Magdaleno se esforzó por publicar en diferentes países de América Latina, concretamente en Chile y Argentina, con escaso éxito. ${ }^{13}$ Así, en una carta que el escritor zacatecano escribió el 15 de julio de 1939 a su amigo argentino César Tiempo, se quejaba de la ausencia de respuesta de Eduardo Mallea: "tiene en su poder 5 relatos míos, con los que usted me hizo el favor de entregarle, y aún no tengo respuesta en ningún sentido" (Magdaleno, 1939a). Siguiendo este hilo de comunicación, tres meses más tarde, insistía Magdaleno con el mismo tema: “'La Nación’ me pagó aquel cuento y no ha vuelto a publicar nada. Quizás no sea menester hacer ya por forzarlos. Me apena muchísimo eso. Tienen otras cosas mías y, o me las devolverán, o acabarán publicándolas" (Magdaleno, 1939b). Entendemos, gracias al testimonio directo de César Tiempo, que al menos uno de esos cuentos que envió Mauricio Magdaleno a Eduardo Mallea

${ }^{13}$ La estrategia de Mauricio Magdaleno fue publicar en América Latina algunas antologías de ensayos que, en realidad, ya había dado a conocer a los lectores mexicanos en diferentes medios periódicos nacionales. En este sentido, sólo consiguió sacar a la luz Vida y poesía (Santiago de Chile: Ediciones Ercilla, 1936) y Rango (Buenos Aires: Editorial Americalee, 1941). 


\section{Hacia una edición crítica de los cuentos de Mauricio Magdaleno}

fue finalmente publicado en La Nación de Buenos Aires, en concreto "Palo ensebado", ${ }^{14}$ sin embargo, desconocemos el destino de los otros.

Ahora bien, en el Diccionario de Escritores Mexicanos, que coordinó la Dra. Aurora M. Ocampo, se incluyen, en el apartado de hemerografía (Ocampo, 2000: 42), cuatro cuentos de Mauricio Magdaleno cuya clasificación debemos poner en duda, a saber: "Tránsito de domingo", ${ }^{15}$ "El agua del sur", "La casa de vecindad"17 y "Una furia en reposo" ${ }^{18}$ Los tres primeros están escritos bajo el título que alumbraba la columna semanal que Mauricio Magdaleno tuvo en El Nacional: "Domingos de El Nacional". ${ }^{19}$ Todas las narraciones tienen el domingo como actor principal, el autor tiende una mirada dominical a la ciudad, a la experiencia y a los recuerdos, dejando traslucir, como siempre, su visión del mundo; impregna a estos relatos un tono melancólico y una mirada desprendida hacia la ciudad; así, para Mauricio Magdaleno, "la ciudad toda no es más que una red de venas desangradas, y al agobio del domingo la vuelve funeraria como un catafalco" (Magdaleno, 1934: 5). A grandes rasgos, en éstos no existe un argumento, se emplean personajes tipo, se refrenda la acción con datos históricos o espacios identificables y, más bien, se describen costumbres. Por último, "Una furia en reposo" es el único - de los cuatro - que no fue publicado en El $\mathrm{Na}$ cional, sino en el suplemento México en la Cultura del periódico Novedades, el 29 de julio de 1956, es decir, dos años después de la primera edición de El ardiente verano. Esta narración, además, en la medida en que supone una rememoración autobiográfica de los tiempos de la Revolución en Aguascalientes, podría ser emparentada con los cuentos "El caimán”, "Cuarto año", "Las carretelas" y "Las víboras"; sin embargo, mientras en éstos se estructura una historia con acciones que describen el carácter de los personajes, un argumento, y se considera la función del lector en la recepción de la historia, en "Una furia en reposo" simplemente se cuenta al interlocutor la anécdota de su encuentro con Pancho Villa. La intención del autor juega, en este caso, como un factor importante a la hora de valorar su realización narrativa: no trasciende su historia personal, sino que sólo comparte con el lector un recuerdo de su infancia relacionado con la historia de México. La polémica de la inclusión o no de "Una furia en reposo" como cuento la zanja el propio Magdaleno cuando incluye una versión

\footnotetext{
${ }^{14}$ Ver la cuarta nota $(* * * *)$ de la Tabla 1.

15 "Tránsito de domingo", en El Nacional (suplemento dominical), 30 de diciembre de 1934, p. 5.

16 "El agua del sur", en El Nacional (suplemento dominical), 3 de febrero de 1935, p. 3.

17 "La casa de vecindad", en El Nacional (suplemento dominical), 26 de mayo de 1935, p. 3.

18 "Una furia en reposo", en Novedades. México en la Cultura, núm. 384, 29 de julio de 1956, p. 3.

${ }^{19}$ Otro artículo de esta misma columna tiene el nombre de "La peluquería de Chóforo Luque en la ciudad de México", en El Nacional, 2. ${ }^{a}$ sección, 12 de mayo de 1935, p. 1. Éste sigue la línea costumbrista del autor.
} 
extendida, y en algunos aspectos diferente, ${ }^{20}$ en Agua bajo el puente (1968), ${ }^{21}$ e incluso señala que fue escrita en 1956, es decir, el mismo año en que publicó una versión más sintética en el periódico. ${ }^{22}$

Por tanto, una investigación hemerográfica previa a la elaboración de la edición crítica debería poner un cuidado especial no sólo en la búsqueda de nuevas versiones de los cuentos, sino también en nuevos testimonios que pudieran relacionarse con cada una de ellas. Además, con respecto a aquellos relatos "limítrofes" genéricamente, tendría que poner atención en la clasificación o categorización de éstos, tomando en cuenta el uso habitual que Magdaleno hacía del cuadro de costumbres, la crónica histórica o el ensayo literario en algunas de sus publicaciones de carácter periodístico.

\section{La editio princeps y las versiones hemerográficas}

Nos gustaría partir del análisis de la que, para efectos de nuestro propósito, consideramos como editio princeps. En concreto, nos referimos a El ardiente verano, cuya primera edición estuvo al cuidado de Sindulfo de la Fuente y de Alí Chumacero y fue publicada por el Fondo de Cultura Económica en el año 1954. La edición suponía el número 17 de Letras Mexicanas, una colección que cumplía, según Agustín Yáñez, una "doble función: incrementar la labor creadora de nuestros hombres de letras, y fincar sólidamente un panorama de nuestra literatura, en especial de la contemporánea que no podrá ser apreciada en el conjunto de sus expresiones representativas si no es mediante el conocimiento de esta colección" (Yañez, 1980: 187-188). Entre la primera edición y sus tres reimpresiones suman 14000 ejemplares, a los que deberíamos añadir los 50000 de la primera edición en el número 35 de la colección Lecturas Mexicanas, para así conocer la cantidad total de ejemplares que circularon - y circulan - en el mercado editorial. Así que los cuentos de dicha colección serían también la editio vulgata.

${ }^{20}$ A modo de ejemplo, y para sustentar la posterior hipótesis respecto a este escrito, algunos de los cambios que introdujo el autor son concretos: mientras en el artículo periodístico dice que la anécdota de las "sábanas" se la contó "el Indio" Fernández, en la libresca afirma que fue su amigo Julián Vidales; en la periodística asevera que el vals que en ese momento tocaban era Rosalía, mientras que en la libresca era Pagaré. Además, la libresca es mucho más amplia e incide en la distinta filiación política de su tío (villista) y de su padre (carrancista).

${ }^{21}$ Mauricio Magdaleno recoge en esta obra tres artículos ("Un teatro", "Cierto instante de Aguascalientes" y "Una furia en reposo") bajo un nombre genérico más amplio: "Historia de Aguascalientes".

${ }^{22}$ Por tratarse de su objeto principal, toda esta argumentación, que ya habíamos apuntado en el trabajo doctoral, la desarrollamos de forma más pormenorizada en la última parte del capítulo "Mauricio Magdaleno y la memoria de Aguascalientes: entre la prensa periódica y la obra literaria", de próxima publicación. 


\section{Hacia una edición crítica de los cuentos de Mauricio Magdaleno}

Eso sí, como ya hemos advertido, sólo tres cuentos constituyen una novedad para el lector, mientras que el resto tuvieron versiones previas, en la mayoría de los casos más esquemáticas, sintéticas y ligadas a las necesidades del autor en ese preciso momento de escritura. De cualquier forma, haber encontrado esas versiones y analizar las variantes que se producen con respecto a los cuentos que se publicaron en la edición en libro constituye una oportunidad para conocer la evolución literaria del autor, su proceso creativo y el contexto real en el que se forjaron. A grandes rasgos, podemos decir que la edición de Chumacero y de Sindulfo de la Fuente para el Fondo de Cultura, que seguramente llevaron a cabo con el propio autor,

adapta los cuentos de éste en un sentido moderno, elimina redundancias innecesarias, estiliza la sintaxis barroca, ahonda en el color local de los personajes, pone de relevancia la acción que se está llevando a cabo con descripciones muy visuales - seguramente por la influencia decisiva del cine que había cultivado el autor durante largos años-, y da una mayor importancia a la explicación y descripción de los referentes históricos mexicanos (Arranz, 2014: 487-488).

Sería muy interesante que todas estas variantes de carácter editorial quedasen consignadas junto con aquellas otras de índole temática o relativas a los procedimientos literarios, para que enriquecieran así el carácter de cada uno de los cuentos.

Para ejemplificar la relevancia de este estudio de variantes nos referiremos al cuento que da título a la colección: "El ardiente verano". La primera versión apareció trece años antes de El ardiente verano en Hoy (núm. 220, 10 de mayo de 1941, pp. 48-49 y 82), bajo el nombre de "Segundo turno". Tan sólo dos años más tarde se publicó la segunda versión en Cuadernos Americanos (vol. VI, núm. 1, enero-febrero de 1943, pp. 229-240), ${ }^{23}$ con otro título, "Mexicanos en Texas", mucho más descriptivo con la realidad política, a diferencia del nombre definitivo que goza de un carácter más metafórico en su alusión al territorio texano. La tercera versión fue, precisamente, la recogida por la colección de cuentos del Fondo de Cultura Económica, que llevaría su título final: "El ardiente verano".

Este último es una versión mucho más extensa que la primera y la segunda, y en gran medida se debe a la inclusión de un gran número de reflexiones históricas, sociológicas y políticas por parte del narrador. Por ejemplo, aquí el autor suprime la igualdad que otorga a negros y mexicanos ante la determinación segregacionista de Estados Unidos, dejando a los mexicanos solos para intensificar el foco de atención - tanto más nacionalista-, y más adelante informa que los negros ya se habían

${ }^{23}$ Recordemos que Cuadernos Americanos fue la revista a la que Alfonso Reyes puso nombre, dirigida en su primera época por Jesús Silva Herzog y cuyo consejo estaba formado tanto por mexicanos como por exiliados españoles, la mayor parte de los cuales constituían la revista España Peregrina, con Juan Larrea a la cabeza. El cuento de Magdaleno, como ficción que es, estaba dentro de la sección "Dimensión imaginaria". 
apartado de entrar al algodón de Deadwood, y que sólo quedan los mexicanos para trabajarlo. La versión definitiva gana en perspectiva histórica, en expresiones populares, en imágenes metafóricas y cinematográficas, en episodios de corte costumbrista, en una mayor prolijidad de sensaciones y sentimientos, en digresiones más maduras, así como en una profundidad psicológica de los personajes, sobre todo en la figura del reverendo, pastor protestante que, además, cambia de nombre, de Peter Livingstoy (en la primera y segunda versión) a Owen H. Heppes (en la contenida en El ardiente verano). También se trastoca el tiempo verbal de la narración: mientras que en la primera y segunda versión el narrador usa el pretérito imperfecto, en la tercera emplea un pretérito perfecto simple que provoca una mayor distancia, gracias a la cual encajan mejor las reflexiones históricas. Como ya pudimos comprobar con el cambio de título, la tierra amplía su sentido metafórico en la tercera y definitiva versión del cuento. Así, mientras en la primera y segunda versión, Rogelio y Lupe sueñan con tener su propio rancho y afirman que "iserá como un pedacito de México para que crezcan los muchachos!” (Magdaleno, 1941: 48; 1943: 231), en la tercera se refieren a que "isería como si trasplantáramos un pedacito de México en el que tú y los muchachos se codearían hasta con los Munson!" (Magdaleno, 1954: 12). Por tanto, mientras que con la primera oración se reivindica la soberanía de ese suelo —un pedazo de México en Texas-, con la segunda simplemente se tiene un acceso igualitario a la propiedad, por eso emplea el verbo "trasplantar", que significaría no ya tener soberanía mexicana en suelo texano (como en las anteriores versiones), sino arrancar algo de la soberanía de México para emplearlo en Texas.

El anterior ha sido sólo un ejemplo, pero en cada uno de los cuentos recogidos en El ardiente verano, especialmente en aquellos cuyas versiones diferentes están más distanciadas, se producen variantes de sumo interés para conocer la transmisión del texto y su recepción a lo largo del tiempo. Lo pudimos comprobar también en el caso del cuento que primero se tituló "Aquella noche" y luego "Teponaxtle", cuyas variantes modificaban muchos aspectos de la narración y del estilo literario del autor (Arranz, 2017b: 133-153). Además, un análisis de las variantes y una profundización en las fuentes podrían contribuir a establecer con claridad el extraordinario parecido que existe entre este cuento de Magdaleno, "Aquella noche" ("Teponaxtle"), y el "Cuento macabro" de Francisco L. Urquizo, un parecido que bordea el plagio, ${ }^{24}$ a no

${ }^{24}$ Desde luego, no sólo el contenido de la historia que se narra es prácticamente idéntico en ambos cuentos - el de Magdaleno y el de Urquizo - , sino que en ocasiones lo describen casi de forma literal. Como muestra, podemos destacar estos fragmentos:

"«-Vamos a volar... Vamos a volar... Vamos a volar...

«Y, efectivamente, volábamos. «iVolábamos!» Volábamos por encima de los cerros, de los ríos, que se retorcían, allá abajo, plateados; de los ranchitos, dormidos y sin luces, como está ahorita El Quebrantadero...»” (Magdaleno, 1933: 38). 


\section{Hacia una edición crítica de los cuentos de Mauricio Magdaleno}

ser que, como cuenta Anatole France en relación con uno semejante entre Moliere y Scarron, ambos autores hubieran bebido de otra fuente común, como estos dos franceses hicieron de La hija de la Celestina de Alonso Jerónimo de Salas Barbadillo (France: 2014: 42). A priori, el cuento de Magdaleno es anterior, porque lo publicó en Madrid en 1933, mientras que el de Urquizo formaba parte del volumen Cuentos y leyendas, impreso por la editorial Cvltvra en $1945 .{ }^{25}$ Desde luego, acercarnos a estas cuestiones a partir de las ediciones críticas de los textos abundaría en un mayor conocimiento de algunos intersticios de la historia literaria mexicana.

Como podemos observar en la Tabla 1 y en el tenor de lo expuesto hasta este momento, Mauricio Magdaleno no escribió cuentos sólo en el año de 1954 - aun cuando la relevancia y la difusión que El ardiente verano tuvo en el sistema literario de la época es indiscutible - sino que lo hizo prácticamente a lo largo de toda su carrera literaria y ligado de forma íntima a su labor en el medio periodístico. Por tanto, el mayor error es someter la obra cuentística de Mauricio Magdaleno a un juicio anacrónico fomentado por el desconocimiento de las fechas de las primeras versiones de sus cuentos, ya que éstas se realizaron desde 1933 hasta prácticamente el año de su fallecimiento en 1986. De hecho, la mayor parte de su obra en este subgénero narrativo se produce antes de 1947, fecha en la que, por ejemplo, Luis Leal señalaba el final del ciclo regionalista y revolucionario, a excepción de que lo retomasen posteriormente, desde diferentes perspectivas, los neorrealistas mexicanos, es decir Córdova, Rulfo, Valadés, García Cantú, entre otros (Leal, 1963: 20-21). Este dato es importante porque, incluso al interior del propio proceso escritural de Magdaleno, la mayoría de los cuentos los creó durante una etapa de escritura caracterizada por un declive literario, ${ }^{26}$ lo cual dice mucho del desahogo que supuso este género en relación con el resto de su obra.

“-Vamos a volar... Vamos a volar.

Y, efectivamente volábamos, volábamos por encima de los cerros y de los ríos y del mar, y de las ciudades cuyas luces veía yo como luciérnagas a mis pies” (Urquizo, 2005: 919).

${ }^{25}$ De hecho, según el Diccionario de escritores mexicanos, no se publicó antes de éste ninguna versión; pero sí dos posteriores: una en el número 439 de la revista México en la Cultura, el 28 de agosto de 1955, en la página 3; y otra, de forma póstuma, en el número 104 de El Búho, el 6 de septiembre de 1987, también en la página 3 (Ocampo, 2007: 20).

${ }^{26} \mathrm{Si}$ seguimos la periodización en etapas creativas del autor que empleamos a lo largo del trabajo doctoral (Arranz, 2014), Mauricio Magdaleno creó las primeras versiones de la mayor parte de los cuentos durante la cuarta etapa que denominamos "Política, cine y declive literario" (1942-1949), a diferencia de El ardiente verano, que ya se encontraría dentro de la quinta etapa, la cual titulamos "Memoria y melancolía. Americanismo y conciencia intelectual" (1950-1956). Por supuesto, estas dos etapas tienen rasgos diferenciadores significativos en el proceso de creación literaria. 
Un ejemplo de esa circunstancia relativa al desbarajuste temporal que se produjo entre la creación de los cuentos de Mauricio Magdaleno y su publicación tiene que ver con el afinado juicio crítico de Emmanuel Carballo, quien incluyó en 1964 el cuento "Cuarto año" en una antología llamada El cuento mexicano del siglo XX (Carballo, 1964: 253-266), pero excluyó los textos de Mauricio Magdaleno de su también antología Cuentistas mexicanos modernos (1956), pese a señalar en el prólogo de ésta que se trataba de los cuentistas cuya producción abarca los años de 1949 a 1956, es decir, un rango que comprendería a El ardiente verano. No obstante, la ausencia de la obra de Magdaleno en esta última antología es intencional, porque Carballo sí tiene presente la publicación de El ardiente verano de 1954 en su Bibliografia del cuento mexicano del siglo XX (1988). Por tanto, Carballo constata que Mauricio Magdaleno no puede ser considerado como cuentista mexicano moderno, a pesar de la estimación que tiene por su obra. Además, no debemos olvidar que los años cincuenta fueron años de transición para el cuento en México, ya que, por un lado, numerosos autores siguieron cultivándolo con apego tanto a los grandes temas nacionales que eran parte de la tradición como a la forma realista, ${ }^{27}$ mientras que, por otro lado, cuatro obras revolucionarían la manera de entender el subgénero: Varia invención (1949) y Confabulario (1952) de Juan José Arreola; El llano en llamas (1953) de Juan Rulfo, y Los días enmascarados (1954) de Carlos Fuentes.

Como no podía ser de otra forma, el propio Mauricio Magdaleno era consciente de este panorama. En una entrevista con Mario Puga en 1956, después de destacar "que la obra de los escritores de la Revolución ha[bía] contribuido en parte considerable a definir el movimiento mismo de nuestro pueblo" (Magdaleno en Puga, 1956: 22), afirma:

Creo en la literatura mexicana y creo en los escritores jóvenes. Ellos son quienes recogerán los frutos de esa amarga y cruda experiencia revolucionaria, son ellos los herederos del acervo histórico de nuestro pueblo. Y ya ha dado frutos excelentes. No lo digo sólo por cuanto a estilo, a dominio del oficio, sino también por el descubrimiento de nuevos ángulos críticos, nuevas modalidades expresivas, nuevos temas. Hay un vigoroso empuje juvenil en nuestras letras, imposible de ignorarlo. Pero de toda esta rumorosa hueste de jóvenes, me quedo con Juan Rulfo y con Juan José Arreola, tan distintos entre sí y tan extraordinarios escritores ambos. ¡Qué fuerte, qué intenso, qué tremendamente dramático es Rulfo! ¡Y qué fino, sutil, irónico y aun satírico, es Arreola! Entrambos están las dos caras de la medalla de nuestras letras contemporáneas. Me es imposible establecer

${ }^{27}$ Entre estas obras podríamos citar las siguientes: El coronel que asesinó un palomo y otros cuentos de Jorge Ferretis; El diosero de Francisco Rojas González; Al viento de Francisco L. Urquizo; Cuentos de los hombres y de la tierra de Alfredo Lara Isaacs; Cuentos de indios. Primer libro de Ramón Rubín; Me lo dïo María Kaimlová de José Mancisidor; Cosas de mi pueblo. Estampas de Yucatán de Ermilo Abreu Gómez. 


\section{Hacia una edición crítica de los cuentos de Mauricio Magdaleno}

preferencias entre uno y otro. El realismo de Rulfo, quizá... Pero, no, imposible. Ambos son excelentes escritores (Magdaleno en Puga, 1956: 23).

No obstante, y aunque con cuentagotas, Magdaleno escribió algún cuento más, pero siempre a partir de esta conciencia de estar ya al margen de la "nueva" literatura. De hecho, tras El ardiente verano, tal y como podemos observar en la Tabla 1, Mauricio Magdaleno sólo publicó cuatro cuentos: "Lunario de la calle del Ahorcado" (1975), "Un vecino de Jerez" (1979), "Las campanas de San Felipe” (1981) y "La bata" (1985). De éstos, la colección póstuma que Lectorum tituló Cuentos completos (2003) sólo incluyó el tercero y lo anunció como un cuento inédito, aunque en sentido estricto no lo era. Dejó entonces sin antologar tres cuentos posteriores a El ardiente verano, además de otros dos que el propio Magdaleno tampoco había coleccionado en el libro del Fondo de Cultura: "[Las mañanas de Schaharazada]" (1927) y "El poder secreto" (1941).

Llama mucho la atención que ni Mauricio Magdaleno incluyera "El poder secreto" en El ardiente verano, ni Cuentos completos lo recuperara. En 1941, el escritor zacatecano inició la publicación de hasta cinco cuentos ("Segundo turno", "El poder secreto", "Leña verde", "Fruta del tiempo" y "Polvo del arrabal") en el semanario Hoy, todos ellos bajo el subtítulo de "un cuento inédito y exclusivo". ${ }^{28}$ Pues bien, tan sólo el que nos interesa ahora no lo contempló en El ardiente verano. A partir del personaje de Román Ortega, "El poder secreto" suponía una crítica a la carrera burocrática dentro de las instituciones del Estado y a las relaciones mediadas por el dinero; no por nada Ortega abandona pesaroso la carrera institucional para abrir un negocio de ocultismo, lo cual provoca que caiga en desgracia y que acabe suicidándose. Desconocemos las razones que llevaron a Magdaleno (o a los editores) a no incluirlo, pero quizá tendrían que ver con los tópicos que trataba, alejados de aquellos del resto de los cuentos, o con la tentación de que se asociara a la propia biografía de Magdaleno y supusiera una crítica al gobierno. A partir de un análisis pormenorizado del semanario Hoy y, en concreto, al dar noticia de estos textos de Magdaleno - la mayoría de los cuales constituyen las primeras versiones - Antonio Sierra García constata la necesidad de una edición crítica de los cuentos: "He integrado este relato [se refiere a 'Segundo turno'] al presente trabajo con la intención de aportar los elementos que justifican la urgencia de una edición crítica de los cuentos de Mauricio Magdaleno" (Sierra, 2007: 235).

Tras El ardiente verano en 1954, Mauricio Magdaleno tardó más de veinte años en publicar otras narraciones cortas, aspecto éste que parece indicar el fin de un ciclo ge-

\footnotetext{
${ }^{28}$ Aunque esto último no era cierto en el caso de "Una noche prodigiosa", ya que, a pesar de tener un nombre diferente, el texto se correspondía a "Aquella noche", que luego acabó titulándose "Teponaxtle".
} 
nérico. Luego, seguramente, resurgió en él la inquietud de adaptar anécdotas, acontecimientos vividos o reflexiones históricas a la forma de este subgénero narrativo, motivo por el cual estos cuatro últimos cuentos colindan la frontera genérica con otros que el autor cultivaba especialmente en formato periodístico, como ya hemos visto. El criterio final que en torno a esa delimitación genérica se adopte en la edición crítica será fundamental para decidir la inclusión de estos últimos - u otros posibles - en el texto crítico.

\section{Metodología para la edición crítica y propuesta de índice}

Las líneas anteriores han procurado poner de manifiesto la necesidad de la elaboración de una edición crítica de los cuentos de Mauricio Magdaleno que tenga como objetivo no sólo la fijación de un texto auténtico a partir del análisis de las diferentes versiones, sino también la puesta en marcha de cualesquiera otras indagaciones, en especial aquellas que nos conduzcan a la comprensión del proceso de escritura de su autor. Esto, como parte de involucrarnos en el problema y la justificación de la propia crítica textual, que según Miguel Ángel Pérez Priego podría reducirse a "cómo llegar a conocer, cómo recuperar el texto que salió de manos o de la voluntad de su autor, y que habitualmente conocemos por una serie de testimonios (más o menos precisos) que se han ido revelando a lo largo del tiempo" (Pérez, 2001: 16). Es notoria la necesidad de adaptar el proceso de edición crítica a las particularidades del proceso creativo y de los textos objeto de estudio, que, asimismo, están muy determinados por la época. Aunque muchas veces los filólogos discrepan en las fases que debe seguir aquel proceso, a grandes rasgos, seguiríamos las dos que en términos generales suele establecer la crítica, y que enuncia así Alberto Blecua: "la primera [...] tiene como fin determinar la filiación o las relaciones que se dan entre los testimonios; la segunda es una fase decisoria, más pragmática, que tiene como fin dar un texto crítico concreto a los lectores" (Blecua, 1983: 33).

Por las características intrínsecas de la fuente, en específico por la participación del propio autor en su constitución, debemos partir del libro de cuentos El ardiente verano. No obstante, aunque consideramos la primera edición del Fondo de Cultura Económica como la editio princeps, y, a su vez, la única en formato de libro - realizada en vida del autor-, y la editio vulgata, es decir, la más difundida entre los lectores, el trabajo fundamental consistiría en establecer relaciones con cada una de las versiones anteriores de los cuentos, de forma que podamos comprender el proceso de transmisión, es decir, su tradición textual. A su vez, y como ha quedado asentado en el presente trabajo, no podríamos dejar de lado los numerosos aspectos que tienen que ver con la crítica genética, tan relevantes en el proceso editorial a partir del siglo Xx. En este sentido, ya Israel Ramírez constató la necesidad de que "una edición crítica 


\section{Hacia una edición crítica de los cuentos de Mauricio Magdaleno}

moderna sea una conjunción filológica de los aportes que puede hacer la textología y la genética" (Ramírez, 2009: 228), en la medida en que esta última "interpreta el proceso de creación de una obra, pero, a la vez, el proceso de creación que sigue el autor de una obra, la génesis y cómo practica su método creativo el escritor" (Ramírez, 2009: 230). Así, privilegiar El ardiente verano sin renunciar a su génesis permitiría una copiosa anotación de la edición crítica, lo cual posibilitaría el conocimiento del proceso creativo del autor y el establecimiento definitivo del texto.

De tal forma, comenzaríamos el trabajo de investigación en cuatro sentidos. En primer lugar, buscaríamos la existencia de un original - ya sea autógrafo o idiógrafo- en el archivo familiar del autor ${ }^{29}$ o en el archivo de la editorial. En segundo lugar, emprenderíamos una búsqueda exhaustiva de carácter hemerográfico para encontrar el mayor número posible de versiones y testimonios de cada uno de los cuentos, ya sea en periódicos, suplementos culturales o revistas, especialmente nacionales, pero también de los diferentes países del ámbito hispánico en donde sabemos, por testimonios indirectos, que Mauricio Magdaleno pudo enviar alguna colaboración. A este respecto, el trabajo hemerográfico podría servir, asimismo, para completar el archivo periodístico del autor, ${ }^{30}$ de tal manera que, por un lado, podamos descartar textos que, por su cercanía genérica, pudieran ser susceptibles de catalogarse como cuentos, $y$, por otro, encontrar otros que pudieran estar relacionados indirectamente con el contenido de algún cuento ${ }^{31}$ o ser la semilla del mismo. ${ }^{32}$ En tercer lugar, procuraríamos buscar la edición del libro que perteneció al propio Mauricio Magdaleno, ya que era muy común que éste corrigiera su obra de forma manuscrita después de haber

${ }^{29}$ Prácticamente la totalidad del archivo de don Mauricio Magdaleno se encuentra dividido entre el Fondo Reservado Mauricio Magdaleno (FRMM) de la Universidad Intercontinental y el Archivo [particular] Rosario Magdaleno (ARM), hija del escritor. De cualquier forma, en ambos ya hemos llevado un arduo proceso de investigación y digitalización de materiales, sin que, hasta la fecha, hayamos encontrado manuscritos de obra publicada, lo cual nos lleva a pensar que Magdaleno nunca guardaba el original o una copia de éste, sino que lo remitía directamente al editor. Una excepción a esto es el manuscrito de "La bata", último cuento que publicó Mauricio Magdaleno, del que sí disponemos de una copia digital (ARM).

${ }^{30}$ En este momento, contamos con aproximadamente un tercio de los textos periodísticos del autor, aunque algunos están incompletos por el deterioro de la fuente original de la que fueron extraídos.

${ }^{31}$ A este respecto, ya tenemos algunos datos de sumo interés, puesto que habría una conexión entre los cuentos de rememoración autobiográfica de sus años en Aguascalientes y algunos de los ensayos contenidos en el libro Agua bajo el puente (1968). Esto lo veremos de forma más clara en el capítulo del libro mencionado en las notas a pie de página 1 y 3 .

${ }^{32}$ Esto último ya nos sucedió cuando elaboramos la edición de El resplandor y encontramos el artículo "El páramo" (ElNacional, 1 de julio de 1934, p. 3), que fue publicado tres años antes. En ese artículo, Mauricio Magdaleno compartía su experiencia como profesor de una normal rural situada en la misma región donde se desarrollaría la novela. 
sido publicada, es decir, atenderíamos a las posibles variantes de autor posteriores a la edición. Por último, tanto en el archivo personal del autor como en fuentes bibliohemerográficas, rastrearíamos testimonios indirectos que enriquecieran el estudio de la génesis y recepción de la obra.

Una vez que contásemos con la reunión de todos los testimonios, previos a la muerte del autor, de cada uno de los cuentos que conformarían la colección y hubiésemos decidido sobre los textos que sí podríamos catalogar dentro de este subgénero narrativo, comenzaríamos propiamente con los diferentes procedimientos de crítica textual que nos llevarían a la propuesta de un texto lo más cercano posible al original, lo cual nos permitiría proporcionar al lector la tradición de éste. La recensio de cada uno de los cuentos - teniendo en cuenta los textos completos, los fragmentos, las variantes de autor y los testimonios indirectos - sería significativa para conseguir una descripción bibliográfica de cada uno de ellos. En principio, para la colación de variantes, consideraríamos la edición del Fondo de Cultura Económica como texto de base de los cuentos que están incluidos en ella, y buscaríamos determinar la filiación o las relaciones producidas entre los diferentes testimonios que consiguiéramos reunir. Como ya hemos dicho anteriormente, la constitutio textus estaría determinada por la elección de El ardiente verano como editio princeps, así que la filiación genealógica de cada uno de los cuentos nos serviría más para la anotación y comentario de las variantes de cierta relevancia.

Por último, llevaríamos a cabo la dispositio textus y, por tanto, la presentación del texto crítico de la manera más clara posible. A este respecto, tendríamos en cuenta la forma lingüística de la época, así como las grafías, palabras, acentuación y puntuación, aunque, al tratarse de textos del siglo xx, las diferencias serían mínimas. Guidaríamos especialmente la disposición del aparato crítico, procurando registrar todas las variantes sustanciales e incluir notas explicativas a pie de página, de tal modo que el lector pudiera apreciar con facilidad los criterios adoptados y las operaciones realizadas como editores de la obra. En principio, adoptaríamos un aparato crítico negativo, señalando las variantes sustanciales rechazadas y el testimonio de donde provienen, confiando, además, en que no fueran excesivas y esto no interrumpiera el acercamiento del lector al texto. De forma paralela, anotaríamos el texto cuando lo estimáramos necesario para aportar al lector información adicional relativa a particularidades lingüisticas, referencias culturales e históricas que encerrase, elementos intertextuales de la propia obra del autor u otros autores, explicación de formas literarias, etcétera. A este respecto, somos conscientes de que también dispondríamos de un estudio preliminar a la obra, motivo por el cual seríamos especialmente cuidadosos con el reparto de la información que se hiciera entre este estudio preliminar y las notas explicativas. De cualquier modo, procuraríamos adoptar siempre los criterios más claros y funcionales para el caso concreto de nuestro texto y pensaríamos siempre en el futuro lector crítico de la obra. 


\section{Hacia una edición crítica de los cuentos de Mauricio Magdaleno}

Aunque hemos constatado que aún queda mucho trabajo por delante para llevar a cabo una buena edición crítica de los cuentos de Mauricio Magdaleno, si consideramos el estado actual de la cuestión, podríamos realizar una primera propuesta de índice, tal y como reflejamos en la Tabla 2. A grandes rasgos, y teniendo como referencia el presumible título de la nueva edición, El ardiente verano y otros cuentos, el índice estaría conformado, en primer lugar, por los cuentos de El ardiente verano en el mismo orden que dispuso la editorial, con la avenencia, en principio, del autor; y, en segundo lugar, por los "otros cuentos", dispuestos a partir del orden cronológico de publicación de la primera versión de los mismos. En el caso de que estos últimos tuvieran varias versiones, en principio, tomaríamos como base para la constitución del texto la última versión en vida del autor, salvo que la colación de variantes nos recomendara otra cosa.

Tabla 2. Propuesta de índice para El ardiente verano y otros cuentos

\begin{tabular}{|c|c|}
\hline Nombre del cuento & Base para la constitución del texto \\
\hline 1. El ardiente verano & $\begin{array}{l}\text { El ardiente verano, México, Fondo de Cultura Económica } \\
\text { (Letras Mexicanas, 17), 1954, pp. 7-39. }\end{array}$ \\
\hline 2. Cuarto año & $\begin{array}{l}\text { El ardiente verano, Fondo de Cultura Económica } \\
\text { (Letras Mexicanas, 17), 1954, pp. 40-59. }\end{array}$ \\
\hline 3. Las carretelas & $\begin{array}{l}\text { El ardiente verano, Fondo de Cultura Económica } \\
\text { (Letras Mexicanas, 17), 1954, pp. 60-84. }\end{array}$ \\
\hline 4. El caimán & $\begin{array}{l}\text { El ardiente verano, México, Fondo de Cultura Económica } \\
\text { (Letras Mexicanas, 17), 1954, pp. 85-99. }\end{array}$ \\
\hline 5. Las Víboras & $\begin{array}{l}\text { El ardiente verano, Fondo de Cultura Económica } \\
\text { (Letras Mexicanas, 17), 1954, pp. 100-119. }\end{array}$ \\
\hline 6. El héroe de Peñuelas & $\begin{array}{l}\text { El ardiente verano, México, Fondo de Cultura Económica } \\
\text { (Letras Mexicanas, 17), 1954, pp. 120-134. }\end{array}$ \\
\hline 7. Llamarada & $\begin{array}{l}\text { El ardiente verano, México, Fondo de Cultura Económica } \\
\text { (Letras Mexicanas, 17), 1954, pp. 135-147. }\end{array}$ \\
\hline 8. Estrellas de noviembre & $\begin{array}{l}\text { El ardiente verano, México, Fondo de Cultura Económica } \\
\text { (Letras Mexicanas, 17), 1954, pp. 148-163. }\end{array}$ \\
\hline 9. Palo ensebado & $\begin{array}{l}\text { El ardiente verano, México, Fondo de Cultura Económica } \\
\text { (Letras Mexicanas, 17), 1954, pp. 164-173. }\end{array}$ \\
\hline 10. Teponaxtle & $\begin{array}{l}\text { El ardiente verano, México, Fondo de Cultura Económica } \\
\text { (Letras Mexicanas, 17), 1954, pp. 174-187. }\end{array}$ \\
\hline 11. Leña verde & $\begin{array}{l}\text { El ardiente verano, México, Fondo de Cultura Económica } \\
\text { (Letras Mexicanas, 17), 1954, pp. 188-201. }\end{array}$ \\
\hline 12. Pasos a mi espalda & $\begin{array}{l}\text { El ardiente verano, México, Fondo de Cultura Económica } \\
\text { (Letras Mexicanas, 17), 1954, pp. 202-216. }\end{array}$ \\
\hline 13. Viernes Santo en Ixtapalapa & $\begin{array}{l}\text { El ardiente verano, México, Fondo de Cultura Económica } \\
\text { (Letras Mexicanas, 17), 1954, pp. 217-233. }\end{array}$ \\
\hline
\end{tabular}




\begin{tabular}{|c|c|}
\hline 14. [Las mañanas de Schaharazada] & El Demócrata, 3 de septiembre de 1925, pp. 3 y 4. \\
\hline 15. El compadre Mendoza & $\begin{array}{l}\text { El resplandor y El compadre Mendoza, México, Promexa } \\
1979 \text { (Clásicos de la Literatura Mexicana; prólogo de } \\
\text { Raúl Cardiel Reyes), pp. 269-286. }\end{array}$ \\
\hline 16. El baile de los Pintos & Concha Bretón, México, Botas, 1936, pp. 183-210. \\
\hline 17. El poder secreto & Hoy, №. 229, 21 de junio de 1941, pp. 42 y 74. \\
\hline 18. Lunario de la calle del Ahorcado & $\begin{array}{l}\text { Anuario } 1975 \text { del Seminario de Cultura Mexicana, México } \\
\text { Ediciones del Seminario de Cultura Mexicana, } 1975 \\
\text { pp. 99-109. }\end{array}$ \\
\hline 19. Un vecino de Jerez & $\begin{array}{l}\text { Excélsior. La Cultura al Día, } 29 \text { de noviembre de 1985, pp. } 1 \\
\text { y } 4 \text {; y Excélsior. La Cultura al Día, } 4 \text { de diciembre de } 1985 \\
\text { pp. } 1 \text { y } 4 .\end{array}$ \\
\hline 20. Las campanas de San Felipe & $\begin{array}{l}\text { Sábado [suplemento de Unomásuno], no }{ }^{\circ} .214,12 \text { de diciem- } \\
\text { bre de 1981, pp. 4-6. }\end{array}$ \\
\hline 21. La bata & Punto, no. 144, 5-11 de agosto de 1985, pp. 17-18. \\
\hline
\end{tabular}

Nota: En color verde destacamos los cuentos que forman parte de El ardiente verano; en azul, los que no se incluyeron en la colección revisada por el autor, pero sí en los Cuentos completos de Lectorum; en amarillo, los que se reunirían por primera vez en una versión libresca.

Fuente: Elaboración propia.

Asimismo, procuraríamos revalorizar los elementos visuales en nuestra edición crítica, ya sea en forma de imágenes del archivo del autor o ya en el rescate de ilustraciones. En este último sentido, sería una lástima desaprovechar la circunstancia de que muchas de las versiones de las publicaciones periódicas estaban ilustradas por relevantes artistas del siglo xx mexicano, tales como Elvira Gascón, José Luis Cuevas, Jesús Ortiz Tajonar, Vicente Rojo, Leopoldo Méndez y Enrique Martínez, entre otros. ${ }^{33}$

\section{Conclusión}

El acercamiento a los cuentos de Mauricio Magdaleno no se había realizado, hasta el momento, desde una investigación profunda de la filiación de los textos, muchos de ellos publicados con anterioridad en periódicos y revistas. Esta ausencia ha impedido hacer un análisis de las variantes de dichos cuentos y, por tanto, no se ha atendido a las inquietudes que iban afectando al autor a lo largo de su proceso creativo. Como hemos podido comprobar, Magdaleno no inicia su periplo por este subgénero narrativo a mediados del siglo xx con la publicación de El ardiente verano, sino, prácticamente, desde el primer tercio del siglo, y lo hace convirtiéndose en un vehículo de transmisión de la

\footnotetext{
${ }^{33}$ Incluso, una versión póstuma de cuentos (Magdaleno, 2017) incluyó nuevas ilustraciones del grabador morelense Sergio Sánchez Santamaría, heredero del Taller de Gráfica Popular.
} 


\section{Hacia una edición crítica de los cuentos de Mauricio Magdaleno}

narrativa corta del siglo XIX. Una edición crítica de los cuentos, es decir, hacer transparente su génesis, su tradición, sus textos y su transmisión permitiría un conocimiento más profundo de los grandes temas que afectaron la conciencia nacional del momento; todo, desde la perspectiva de un autor cuya vida recorrió casi la totalidad del siglo xx.

Esta encrucijada en la que se encuentra la obra cuentística de Mauricio Magdaleno y las particularidades del proceso de creación que se han expuesto a lo largo de la justificación de esta propuesta, en especial las que lo caracterizan como un escritor asiduo en las publicaciones periódicas y consciente de la tradición literaria de finales del siglo XIX, suponen un reto ilusionante para llevar a cabo esta edición crítica. Hacerlo, nos acercaría a la experiencia literaria, teniendo en cuenta que, como decía Alfonso Reyes,

la contextura íntima de un libro no se muestra con sólo exhibir los materiales de la cantera en que se ha labrado. La operación de mostrar el tejido de un libro consistiría más bien en ir analizando todos los motivos y estados mentales que han determinado cada una de las páginas, hasta donde el escritor o el sujeto pueda analizarse a sí mismo sin usurpar las funciones de un psicólogo (Reyes, 1962: 124).

Tendríamos así la posibilidad de escuchar el hálito de vida de la aparente mecánica con la que se imprimen los textos.

\section{Algunas ilustraciones de las versiones periodísticas de los cuentos}

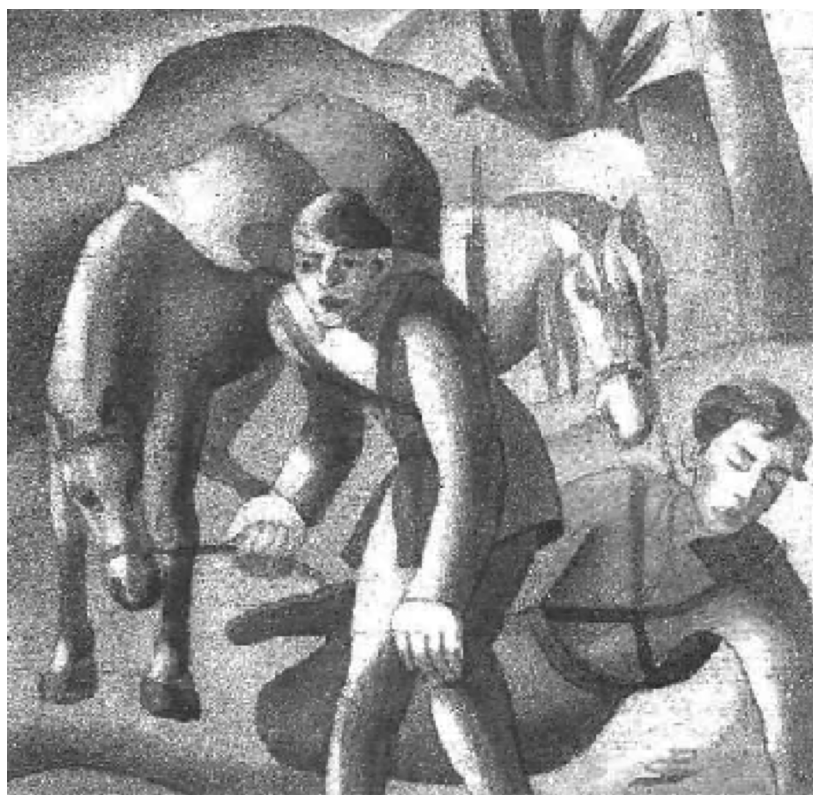

Ilustración, de autor desconocido, para el cuento "Aquella noche" (Estampa, 1933) 


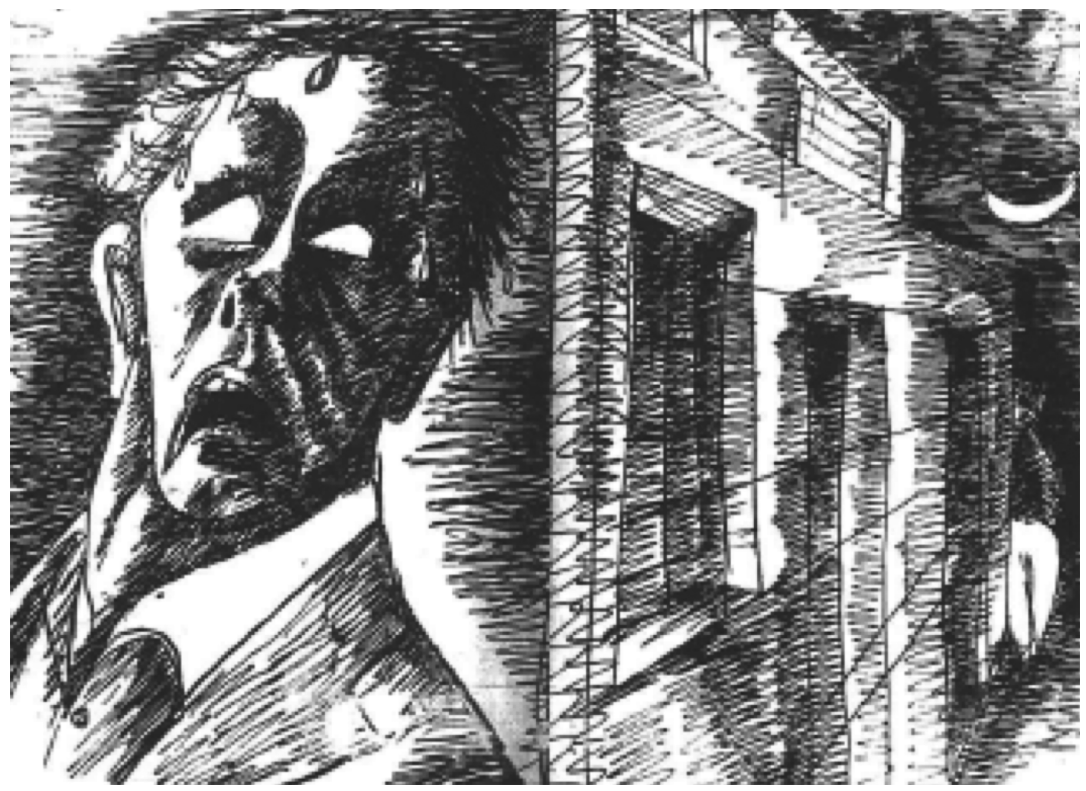

Ilustración, de Elvira Gascón, para la edición de "Pasos a mi espalda" (Novedades,1951)

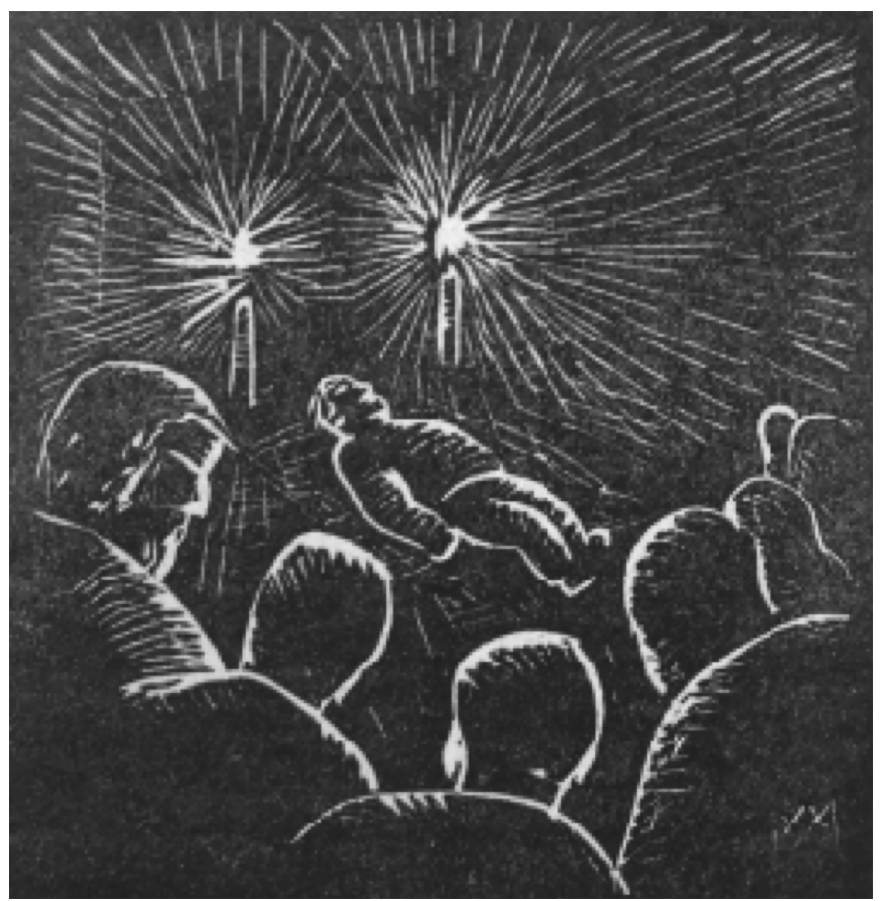

Ilustración, de autor desconocido, para el cuento "Leña verde" (Mundo. Una revista para todo el mundo, 1945) 
Hacia una edición crítica de los cuentos de Mauricio Magdaleno

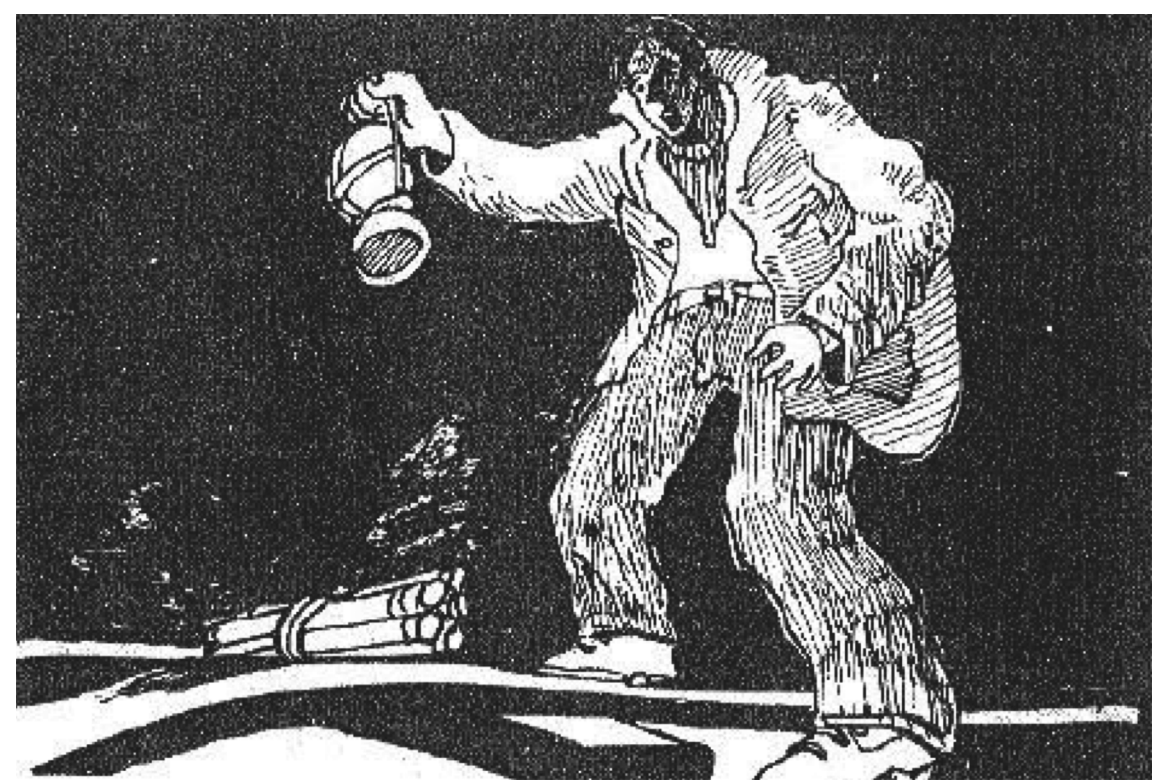

Ilustración, de Enrique Martínez, para "El héroe de Peñuelas" (Cuentos de la provincia, s/a)

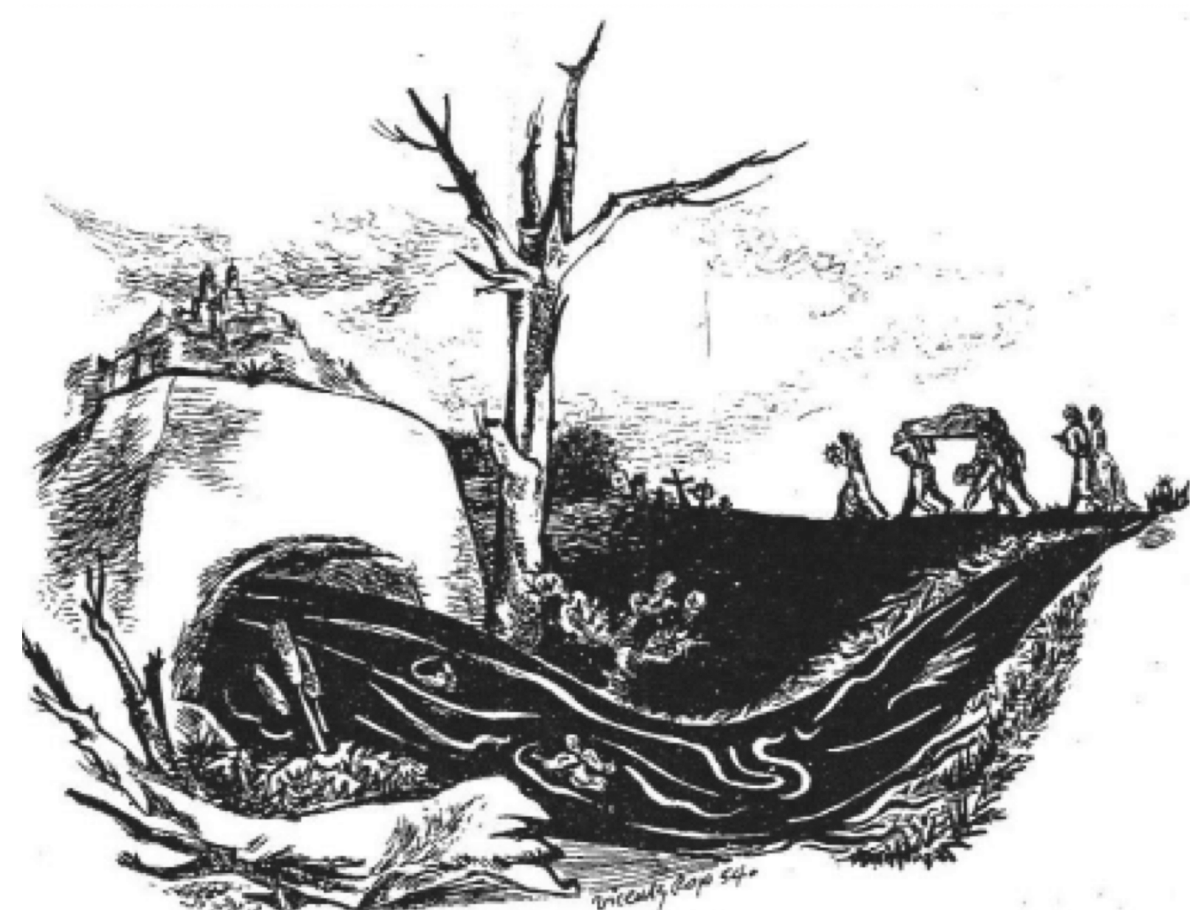

Ilustración, de Vicente Rojo, para el cuento "El caimán” (Universidad de México, 1954) 


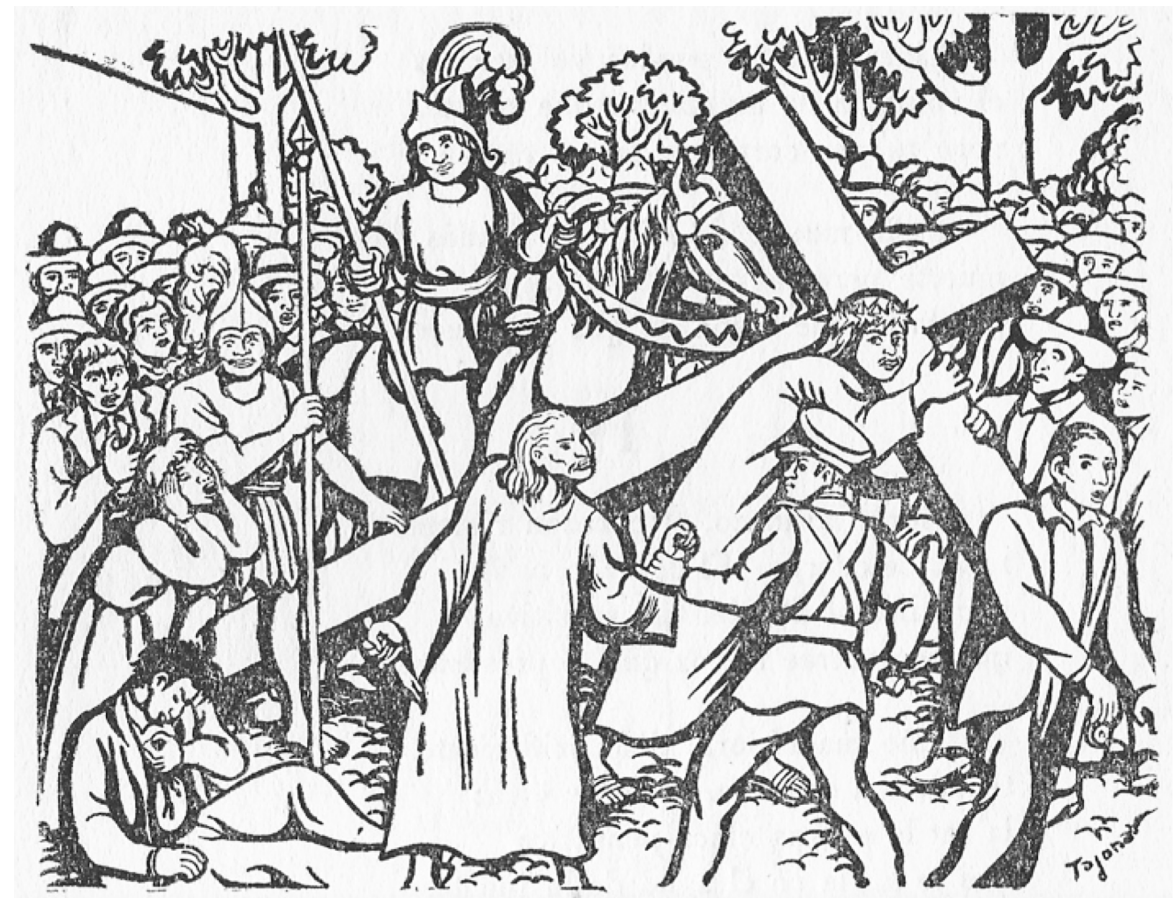

Ilustración, de Jesús Ortiz Tajonar, para el cuento

"Viernes Santo en Ixtapalapa" (América, 1954)

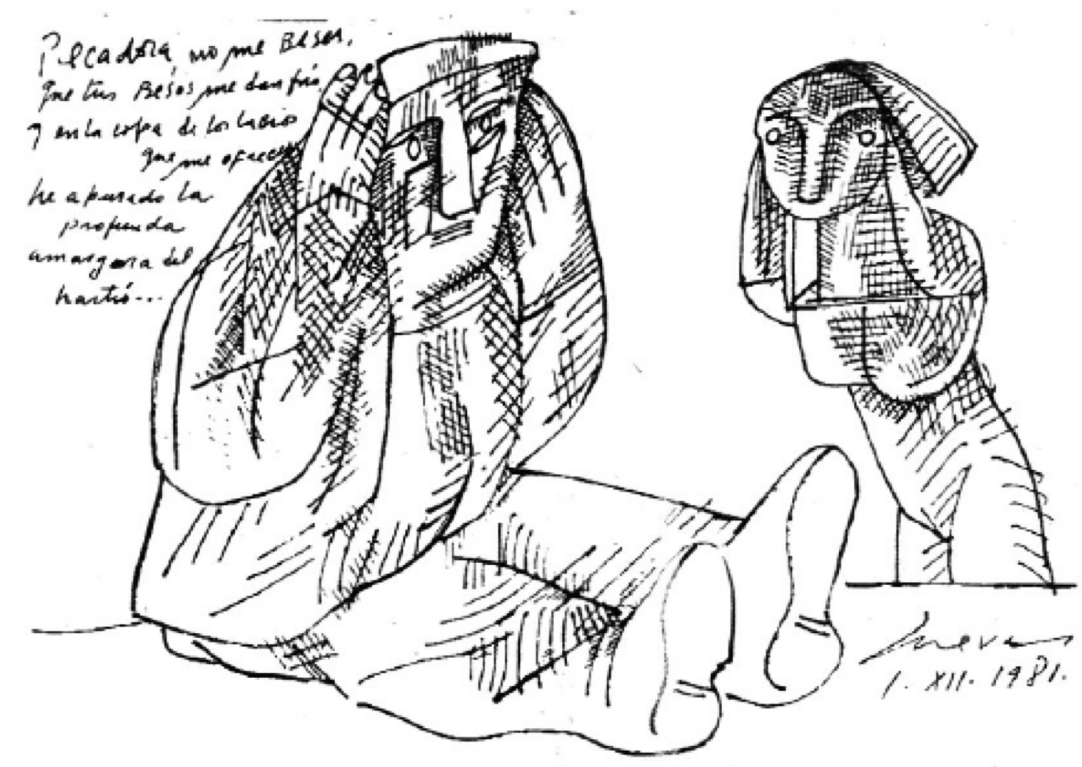

Ilustración, de José Luis Guevas, para “Un vecino de Jerez” (Proceso, 1981) 


\section{Hacia una edición crítica de los cuentos de Mauricio Magdaleno}

\section{Bibliografía $^{34}$}

Arranz, Conrado J.

"El universo literario de Mauricio Magdaleno (1906-1986)". Tesis de doctorado. Madrid: Universidad Nacional de Educación a Distancia, 2014.

"Para permanecer en la frontera [estudio preliminar]", en Mauricio Magdaleno. Cuentos de la Revolución Mexicana. Querétaro: Universidad Autónoma de Querétaro, 2017a, 11-33.

"Variantes y variaciones en un cuento sobre la Revolución Mexicana: 'Teponaxtle', de Mauricio Magdaleno", en Marco Antonio Chavarín González y Josué Sánchez Hernández (editores). Literatura de la Revolución Mexicana: otras lecturas a 101 años de Los de abajo. San Luis Potosí: El Colegio de San Luis, 2017b, 133-153.

Blecua, Alberto

Manual de crítica textual. Madrid: Editorial Castalia, 1983.

Carballo, Emmanuel

Cuentistas mexicanos modernos. México: Libro-Mex, 1956.

Bibliografia del cuento mexicano del siglo Xx. México: Universidad Nacional Autónoma de México, Coordinación de Difusión Cultural, 1988 (Serie Textos, 3).

Carballo, Emmanuel (editor)

El cuento mexicano del siglo Xx. México: Empresas Editoriales, 1964.

Curiel Defossé, Fernando

"sigloveinte@lit.mex. Recorrido en 4 escalas", en (an)ecdótica, volumen IV, número 2 (julio-diciembre 2020), 31-60.

Eagleton, Terry

Una introducción a la teoría literaria. 2. ${ }^{a}$ edición. Traducción de José Esteban Calderón. México: Fondo de Cultura Económica, 2014.

France, Anatole

Apología del plagio. Traducción de Manuel Serrat Crespo. Palma, España: José J. de Olate, Editor, 2014.

LEAL, Luis

"El cuento de la revolución mexicana", en El Libro y el Pueblo, época IV, número 7 (noviembre de 1963), 20-21.

\footnotetext{
${ }^{34}$ En la bibliografía final sólo incluimos las fuentes de las que hemos tomado citas, textuales o de paráfrasis, para nuestro artículo, y no de las obras de Mauricio Magdaleno a las que nos referimos para proponer la edición crítica, ya que entendemos que éstas quedan debidamente referidas en las tablas que forman parte del artículo, evitando así una redundancia innecesaria.
} 


\section{Magdaleno, Mauricio}

“Tránsito de domingo", en El Nacional (suplemento dominical) (30 de diciembre de 1934), 5.

"Carta de Mauricio Magdaleno a César Tiempo", 15 de julio de 1939a. Archivo César Tiempo, Fondo Centro de Estudios Nacionales (Archivo ct, Fondo CEN), Archivos y Colecciones Particulares, Biblioteca Nacional de la República Argentina.

"Carta de Mauricio a Magdaleno a César Tiempo", 26 de septiembre de 1939b. Archivo César Tiempo, Fondo Centro de Estudios Nacionales (Archivo CT, Fondo CEN), Archivos y Colecciones Particulares, Biblioteca Nacional de la República Argentina.

“Segundo turno", en Hoy, número 220 (10 de mayo de 1941), 48-49 y 82.

"Mexicanos en Texas", en Cuadernos Americanos, volumen VI, número 1 (enero-febrero de 1943), 229-240.

El ardiente verano. México: Fondo de Cultura Económica, 1954.

El compromiso de las letras. México: s. e., 1958.

Cuentos completos. Prólogo de Eduardo Antonio Parra. México: Lectorum, 2003.

Cuentos de la Revolución Mexicana. Selección y estudio preliminar de Conrado J. Arranz. Querétaro: Universidad Autónoma de Querétaro, 2017.

\section{Medina Ávila, Virginia}

"Mauricio Magdaleno: el crédito que nadie lee. El guión cinematográfico, literatura para ser admirada". Tesis de maestría. México: Universidad Nacional Autónoma de México, 1998.

\section{Molina, Silvia}

"Entrevista a Mauricio Magdaleno. Un artista en la historia de México", en Sábado. Suplemento cultural de Unomásuno, número 214 (12 de diciembre 1981), 3-4.

NORA, Pierre

Pierre Nora en Les lieux de mémoire. Prólogo de José Rilla. Traducción de Laura Masello. Montevideo: Trilce, 2008.

Ocampo, Aurora M. (coordinadora)

Diccionario de escritores mexicanos. Siglo Xx. Desde las generaciones del Ateneo y novelistas de la Revolución hasta nuestros días. Tomo V (M). México: Universidad Nacional Autónoma de México, 2000.

Diccionario de escritores mexicanos. Siglo Xx. Desde las generaciones del Ateneo y novelistas de la Revolución hasta nuestros días. Tomo IX (U-Z). México: Universidad Nacional Autónoma de México, 2007. 


\section{Hacia una edición crítica de los cuentos de Mauricio Magdaleno}

PARRA, Eduardo Antonio

"Prólogo", en Mauricio Magdaleno. Cuentos completos. México: Lectorum, 2003, 7-17.

Pérez Priego, Miguel Ángel

Introducción general a la edición del texto literario. Madrid: Universidad Nacional de Educación a Distancia, 2001.

PugA, Mario

"Mauricio Magdaleno [Entrevista a Mauricio Magdaleno]", en Revista de la Universidad de México (8 de abril de 1956), 20-23.

RAMírez, Israel

"Genética y crítica textuales en la edición de obras contemporáneas", en Belem Clark de Lara, Concepción Company Company, Laurette Godinas y Alejandro Higashi (editores). Crítica textual. Un enfoque multidisciplinario para la edición de textos. México: El Colegio de México/Universidad Nacional Autónoma de México/Universidad Autónoma Metropolitana, 2009, 209-231.

Reyes, Alfonso

"La experiencia literaria", en Obras Completas. Tomo XIV. México: Fondo de Cultura Económica, 1962, 17-233.

"El deslinde", en Obras Completas. Tomo XV. México: Fondo de Cultura Económica, 1963, $15-422$.

Sierra García, Antonio

"La participación de los escritores en la revista Hoy (1937-1942)". Tesis de Maestría. México: Universidad Nacional Autónoma de México, 2007.

Tiempo, César

“Carta de César Tiempo a Mauricio Magdaleno”, 5 de julio de 1939. ARM.

URQUizo, Francisco L.

"Cuento macabro", en Obras escogidas. México: Fondo de Cultura Económica/Instituto Nacional de Estudios Históricos de las Revoluciones de México/Gobierno de Coahuila, Asociación Cívica General de División Francisco L. Urquizo, 2005, 915-923.

YÁÑEz, Agustín

"Letras mexicanas", en Libro conmemorativo del 45 Aniversario del Fondo de Cultura Económica. México: Fondo de Cultura Económica, 1980, 186-188. 